TAO, Vol. 15, No. 3, 269-310, September 2004

\title{
A Report from the RIKEN International Frontier Research Project on Earthquakes (IFREQ)
}

\author{
Seiya Uyeda ${ }^{1, *}$, Toshiyasu Nagao $^{1}$ and Haruo Tanaka ${ }^{1}$
}

(Manuscript received 6 April 2004, in final form 11 June 2004)

\begin{abstract}
Mitigation of seismic hazards requires integration of science and human action, namely the science of earthquakes, anti-seismic engineering and socio-political measures. In this paper, we will be primarily examining the problem of saving human life from earthquakes. Loss of human life from earthquakes is caused overwhelmingly by the collapse of houses and buildings within less than a few minutes of the main shocks. When structural damage is reduced, most other seismic hazards will also be reduced. On top of that, if short-term prediction could be made, casualties would be further reduced dramatically. We review the state of the art in short-term prediction, in particular recent progress in approaches using electromagnetic phenomena.

The RIKEN International Frontier Research Project on Earthquakes (IFREQ) has demonstrated the existence of pre-seismic ultra-low frequency (ULF) geo-electric potential changes, a claim that has long been made by the Greek VAN group. In addition, IFREQ has been able to verify the precursory signatures of ULF geomagnetic variations. A review is also made for another promising method using pre-seismic over-the-horizon transmission of VHF $(\sim 100 \mathrm{MHz}) \mathrm{FM}$ radio waves. Thus, the reinforcement of existing structures and enhancement of short-term prediction research are the two keys for seismic hazard mitigation.
\end{abstract}

(Key words: Loss of life, Short-term earthquake prediction, Seismo-electromagnetic phenomena)

\footnotetext{
${ }^{1}$ Earthquake Prediction Research Center, Tokai University, Shizuoka, Japan

* Corresponding author address. Prof. S. Uyeda, Earthquake Prediction Research Center, Tokai University, 3-20-1, Shimizu Orido, Shizuoka, 424-8610, Japan; E-mail: suyeda@st.rim.or.jp
} 


\section{INTRODUCTION}

Earthquakes are caused by sudden fault motions. It has long been known that the global distribution of earthquakes is far from uniform. While mid-oceanic ridges are characterized by linear distribution of relatively small earthquakes, large disastrous earthquakes occur mainly in the circum-Pacific belt and in the wide zone between Eurasia and the southern continents. The reason why they are distributed in this manner is explained by plate tectonics. Although plate motions have been essentially steady for millions of years, the seismicity of the globe displays variation on finer time-scales of tens of years, as shown in the upper panel of Fig.1. It seems significant that the variations in the loss of life shown in the lower panel of Fig.1 are very different from those of seismicity. For instance, the two largest earthquakes, the 1960 M9.5 Chilean and 1964 M9.2 Alaskan earthquakes, caused much less loss of life compared to the much smaller 1923 M7.9 Kanto and 1976 M7.8 Tangshan earthquakes. Disaster increases with population density. In this paper, we intend to focus our attention on the problem of saving human life from earthquakes as a follow up to our recent publication (Uyeda and Meguro 2004).

Experiences all over the world show that, almost without exception, the majority of victims are killed by the collapse of buildings at the moment of the main shocks. An example is shown in Fig. 2 (Nishimura et al. 1997): the 1995 M7.3 Hyogoken Nanbu (or Kobe) Earthquake took over 5,500 human lives. Almost $90 \%$ of the victims were killed in their own houses. Moreover, over $90 \%$ of casualties were killed within less than 15 minutes after the quake before any organized rescue operation had started. Many victims of earthquakes are also killed by fire; however, it's worth noting that most large fires start due to collapsed housing. The best way to prevent fires getting out of control is to prevent housing from collapsing. There is no doubt that if housing can withstand the shaking, loss of human life is much reduced. Thus, the most effective and highest priority countermeasure against loss of human life is to strengthen houses. Take for example the recent December 26, 2003, M6.7 Bam Earthquake in Iran, where there were more than 30,000 casualties due to the collapse of houses made primarily by adobe brick.

Another important issue in the prevention of loss of life is that of prediction. Clearly many lives can be saved if residents can be forewarned. The impact of short-term prediction on casualties may also be dramatic in the case of large earthquakes that generate tsunamis. Earthquake prediction is usually classified into three categories: long, intermediate and short-term predictions. They are different in methodology, accuracy and purpose. Long-term prediction deals with the probability of earthquake occurrence on time scales of 10 to $10^{2}$ years, based mainly on geologic studies of faults and historic records of earthquakes, while intermediateterm (1 to 10 years) prediction uses more recent data including seismological observations. Long and intermediate-term predictions are essentially statistical likelihood estimates and can be useful guidelines for planning of cities, railroads and infra-structures of the community. For the purpose of saving human life, it is obvious that the short-term (less than a day to months) prediction is most effective. Short-term prediction is based on some definite precursors. Systematic short-term earthquake prediction research started in the 1960's in several countries including Japan, USA, Soviet Union, and China (Rikitake 1976). In the 1970's, optimism 

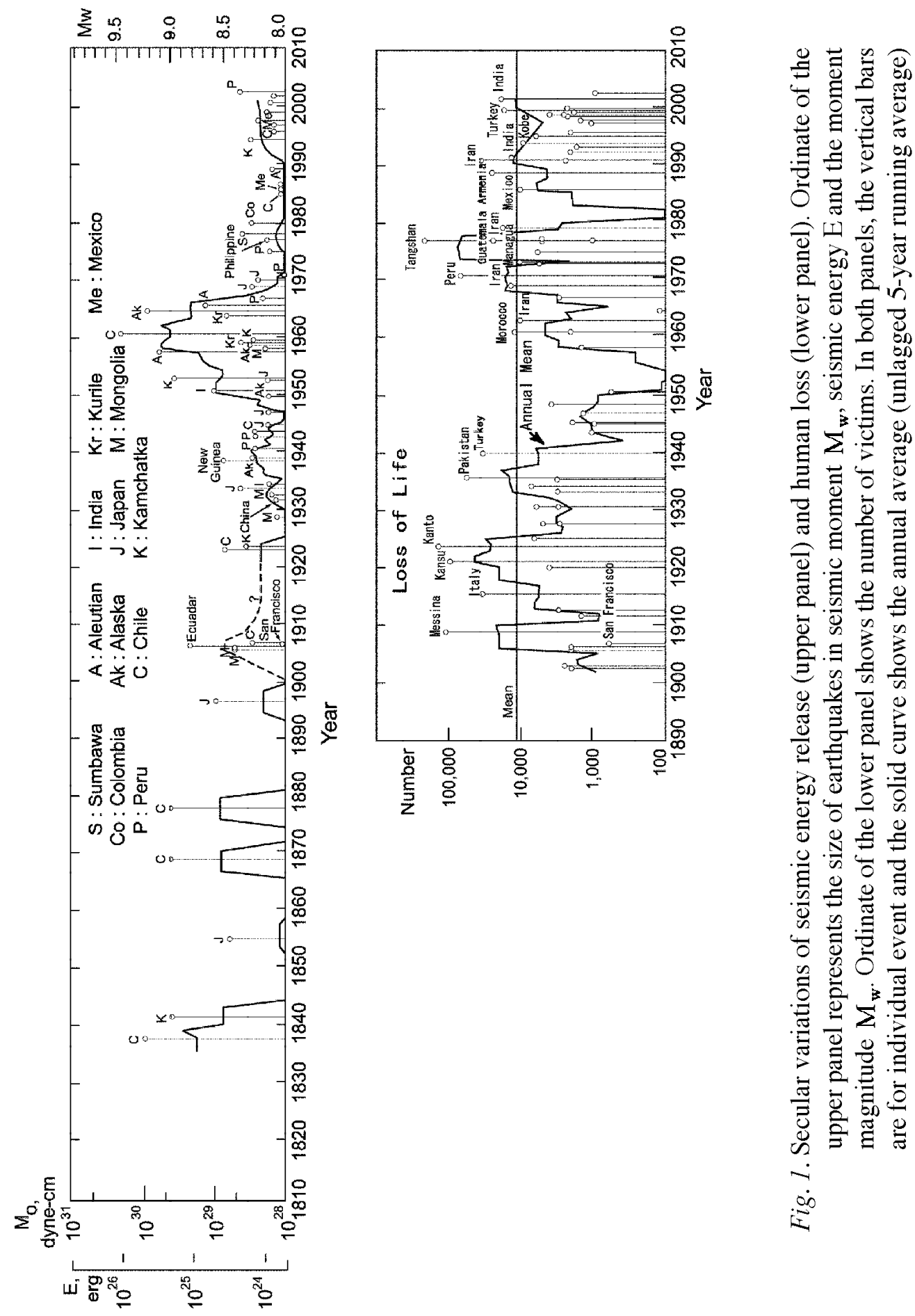

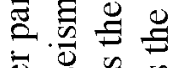

를

记

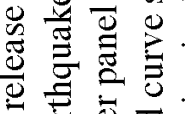

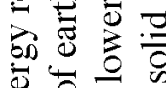

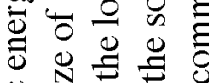

.

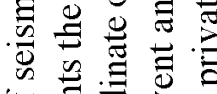

○

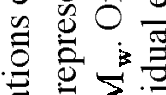

.

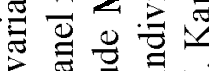

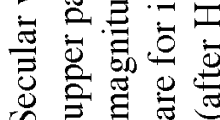

$\sim$

$\dot{\infty}$ 


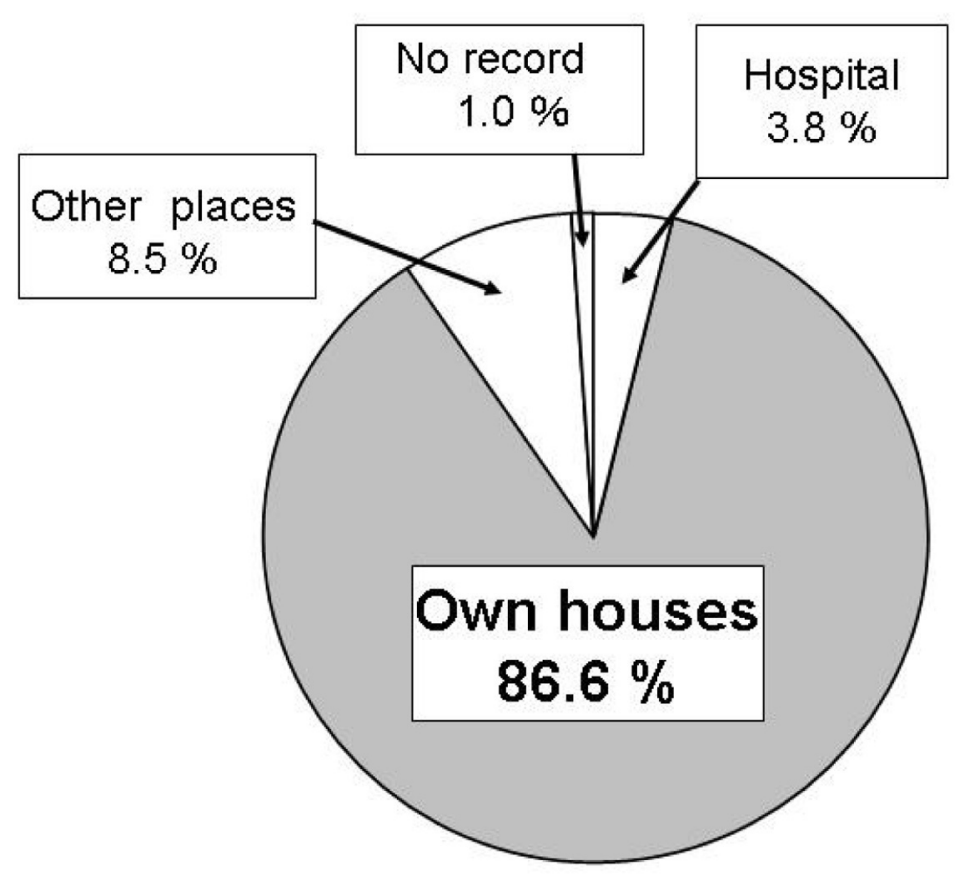

Fig. 2. Places where people died (in Kobe City). (After Nishimura et al. 1997)

prevailed due to encouraging developments, such as the dilatancy models (e.g., Scholz et al. 1973) and the successful prediction of the 1975 M7.2 Haisheng earthquake in China (e.g., Chen et al. 1990). However, no generally recognized successes have followed, causing the research community to become pessimistic. Apparently, the failure of predicting the earthquake in Parkfield, California (Andrews 1992), where the World's best monitoring system was in operation, discouraged some American researchers. It is our belief, however, that shortterm earthquake prediction is possible because many promising approaches are emerging.

\section{SHORT-TERM EARTH QUAKE PREDICTION}

In 1978, the Earthquake Prediction Program of Japan designated eight "areas of special observation" and two "areas of intensified observation" (inset of Fig. 3), based on seismicity and socio-economic importance (Hamada 1990). This can be taken as a set of nationwide intermediate-term predictions. It seems remarkable that these intermediate predictions have been largely fulfilled, because most of the large earthquakes after 1978 have occurred in or near the "areas of special observation" as also shown in Fig. 3. However, none of these earthquakes, including the Kobe earthquake, was predicted in the short-term. The main reason 


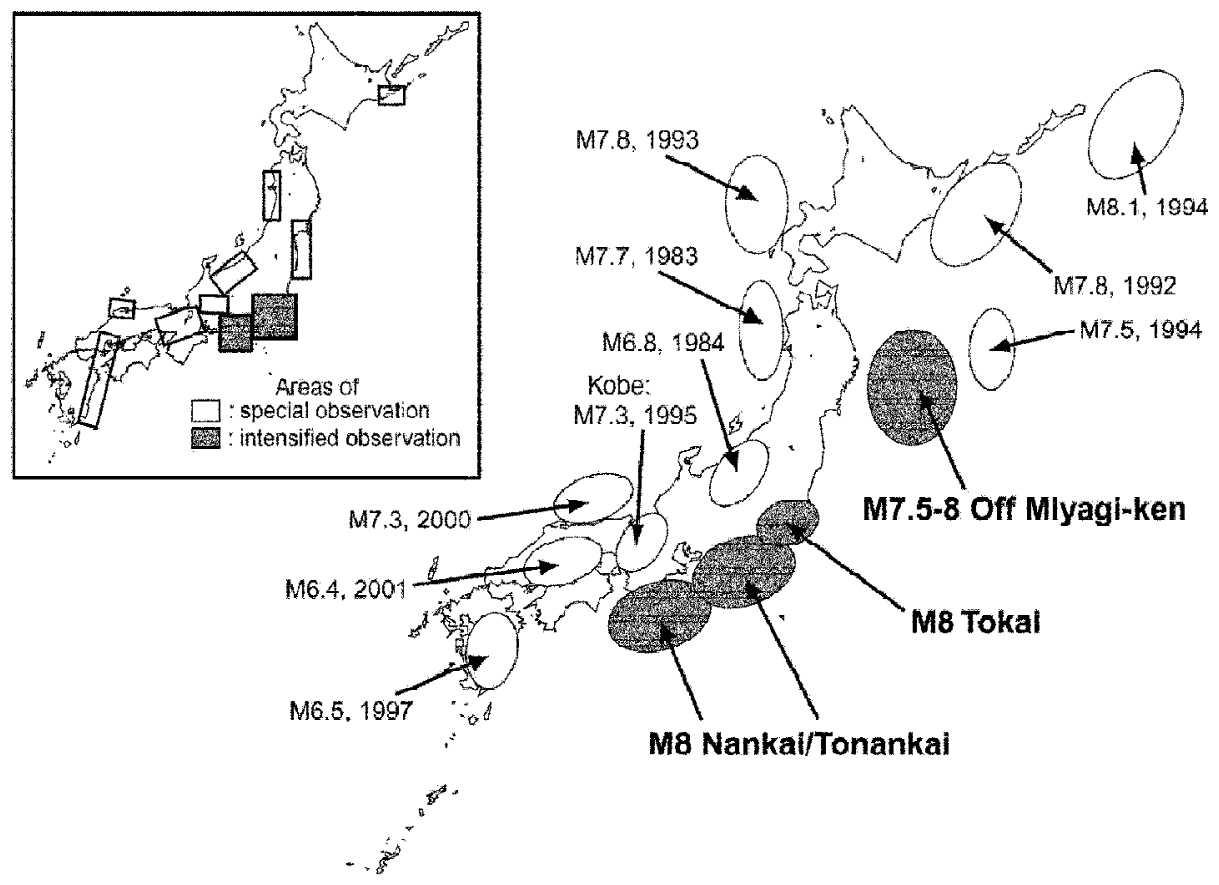

Fig. 3. Inset shows the eight "areas for special observation" (empty rectangles) and two "areas for intensified observation" (filled rectangles), selected by the Japanese Earthquake Prediction Program in 1978. Main figure shows the roughly estimated source regions of major earthquakes which occurred afterwards (smaller letters) and expected earthquakes (larger letters).

for this was simply that there was no organized effort aimed at short-term prediction in these "areas of special observation". In actual fact, implementation of prediction methods, such as densely distributed tilt-meter and strain-meter monitoring equipment, have been installed, but in two "areas of intensified observation" where major earthquakes have not yet occurred. The two "areas of intensified observation" were selected because a great earthquake exceeding magnitude 8 was expected to occur there soon, based on long-term predictions. This future earthquake has even been given a name: the Tokai (meaning East Sea in Japanese) earthquake. The postulated epicentral area has lately been extended westward as in the main map of Fig. 3, so that it is now often called the Tonankai/Nankai (East South/South Sea) earthquake (see Fig. 4).

When people assert that the search for earthquake precursors has proven useless, they often overlook the fact that scientific and effective precursor research has seldom been carried out anywhere. Certainly, seismic networks have been considerably upgraded, so that even micro-earthquakes can now be detected and located precisely. Precursory changes in local/ 
regional seismicity, such as fore-shock activity and quiescence, may be detected (e.g., Sobolev et al. 2002), but seismic networks are not suited, by definition, for detecting non-seismic precursors. An earthquake is a mechanical vibration of the ground but since it is caused by breaking of the earth's crust, which, unlike a flawless piece of glass, has highly heterogeneous structures, it is likely that its preparatory process has various facets which may be observed before a final catastrophe. Therefore, the science of earthquake prediction should be multidisciplinary. Pre-seismic changes in levels and chemistry of ground water are providing potentially useful data for short-term prediction (e.g., Silver and Wakita 1996; Koizumi et al. 1999). Macro-anomalies, such as anomalous animal behaviors may also be useful (e.g., Ikeya et al. 1997).

The introduction of the global positioning system (GPS) has revolutionized geodetic science. Movements of the earth's surface can now be tracked with the precision of $1-0.1 \mathrm{~cm}$. Fig. 4 is an example to illustrate the occurrence of anomalous crustal movements in the Tonankai area, Japan. The displacement after March 2001 shown in (A) has been drastically different from the longer-term average shown in (B). The central coastal area, in particular, has moved south-eastward against the north-westward subduction of the Philippine Sea Plate. Whether or not this indicates a pre-slip of the feared great Tonankai earthquake cited above or a manifes-

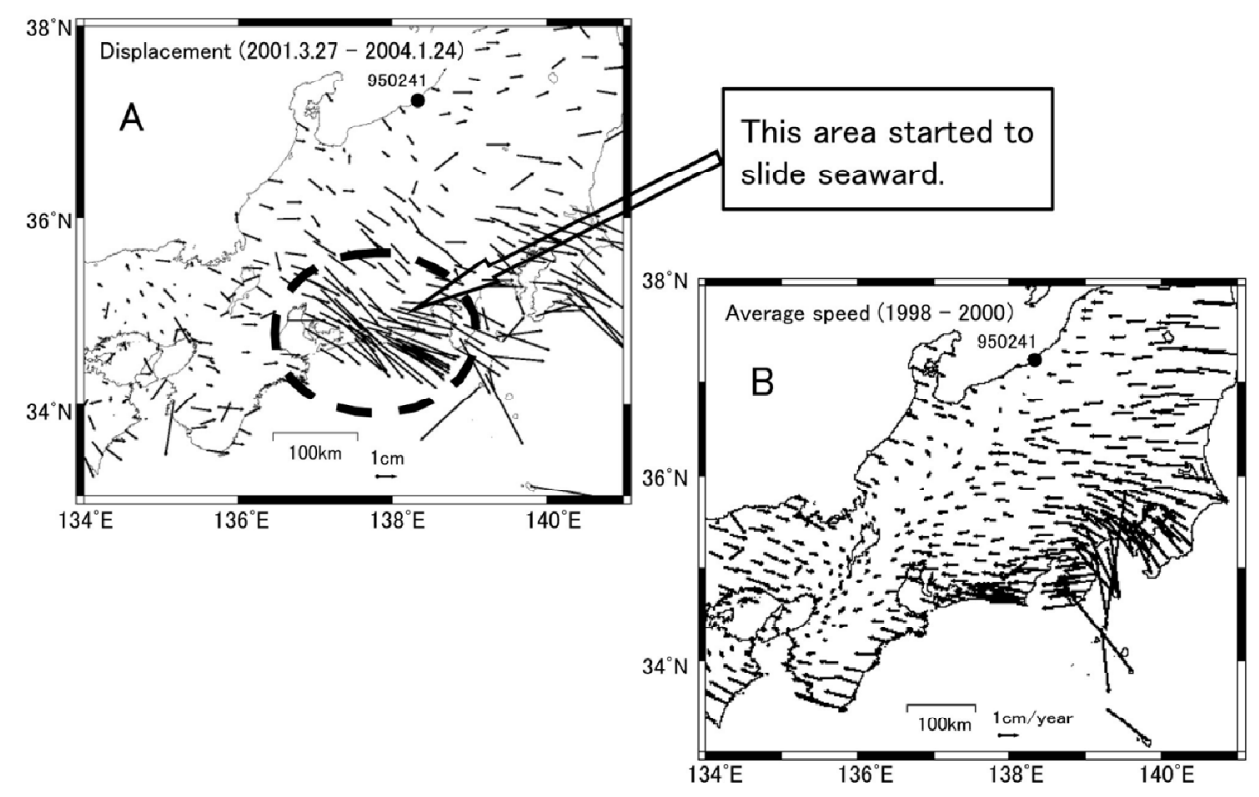

Fig. 4. GPS observation of the displacement of central Japan relative to Point 940241 (After website of Geodetic Survey Institute of Japan). A. Displacement in cm from March 27, 2001 to January 24, 2004. B. Average speed in cm/year for 1998-2000. 
tation of a slow earthquake is not clear. But, such observations were not possible before GPS.

Another novel direction of research is focused on the possibility of electromagnetic precursors. Since earthquakes are sudden fault motion that involves fracture of rocks and/or frictional movements of rock masses, it is anticipated that the seismogenic process involves electromagnetic phenomena. There have been a number of positive reports during the last decade. Evidence has been found for pre-seismic electromagnetic (EM) phenomena in a wide frequency range $\left(10^{-3} \sim 10^{8} \mathrm{~Hz}\right)$, from many parts of the world, including Greece, Japan, Russia, China, Taiwan, Armenia and Italy [e.g., Lighthill (Ed.) 1996; Balassanian et al. 1997; Hayakawa and Molchanov (Eds.) 2002; Uyeda and Park (Eds.) 2002, and references therein.]. We will present the state of the art of electromagnetic (EM hereafter) aspects of earthquake (EQ hereafter) prediction research in the following.

\section{THE VAN METHOD}

\subsection{Outline of the VAN Method.}

The VAN group has been developing a short-term EQ prediction method since the early 1980's (e.g., Varotsos and Alexopoulos 1984a, b; Varotsos et al. 1996a). The most comprehensive and up-dated monograph on the VAN method will be published soon (Varotsos 2004). The method claims that EQs in Greece with Ms (ATH) (magnitude, M, announced by the Seismological Institute of the National Observatory of Athens, SI-NOA) greater than 5 can be predicted within an error of $100 \mathrm{~km}$ in epicentral location and 0.7 of an unit in M. The time of EQ occurrence is claimed to be from several hours (in the case of aftershocks) to two weeks after signal detection, or it can be up to several weeks for repeated and prolonged signals (SES activity and GVEF, see below).

In the VAN method, one monitors continuously the geoelectric potential changes. At each station, several short dipoles with different lengths $(50-200 \mathrm{~m})$ in both EW and NS directions and a few long dipoles $(2-20 \mathrm{~km})$ in appropriate directions are installed. Such a multiple dipole system is necessary for noise rejection. Digitally recorded data on geoelectric potential changes are transmitted in real time to the central station in Athens through public telephone lines.

The VAN scientists claim that some of the observed geoelectric potential gradient changes with amplitude of the order of $1 \mathrm{mV} / 100 \mathrm{~m}$ are indeed precursors to EQs and call them Seismic Electric Signals (SES). There are three types of precursory signals: namely single SES, SES Activity and Gradual Variation of Electric Field (GVEF). Single SES is a signal isolated in time and precedes a single EQ, whereas in SES activity a number of SES appear within a short time, such as within a few hours or a day, and are followed by several seismic events. SES can have varied waveforms. GVEF, having a duration of many hours to days, is reported to appear weeks before a large [Ms(ATH) 15 5.5] EQ. GVEF has amplitude of an order of magnitude larger than usual SES. Similar long variations were observed earlier by Sobolev in Kamchatka (Sobolev 1975) and more recently by Nagao and others in Japan (Nagao et al. 1996a). 
The time lag between signals and EQs is different for different types of signals. It is between several hours (for aftershocks) and two weeks for a single SES. For SES activity, the sequence of events seems more complicated taking a time span of several weeks or more. As to the time sequence of SES and EQs, a new concept called "Natural Time Domain" has recently been introduced by the VAN group, as will be mentioned later.

\subsubsection{Selectivity: (how to predict an epicenter)}

The VAN research has made two major discoveries. One is in so-called selectivity, which consists of two important areas. The first is that there are only selected sites which are sensitive to SES (sensitive sites). The second, which is even more striking, is the fact that a sensitive site is sensitive only to SES from some specific focal area or areas that are not always close to them. A map identifying those focal area(s) is called the selectivity map of the site (Fig. 5). Conversely, once the selectivity map has been established, it provides the means to predict the epicenter of the impending EQ. This selectivity rule, which is highly reproducible, was discovered empirically. The intriguing process of establishing a selectivity map of the Ioannina station has been examined in detail (Kondo et al. 2002). In a physical sense, the sensitive sites and corresponding focal area(s) have to be somehow selectively electrically connected as modeled by the VAN group (Varotsos et al. 1998; Sarlis et al. 1999). It would even be consistent with the view that the amount of electric current density at the source would have to be unrealistically huge for SES to travel hundreds of $\mathrm{km}$ in a homogeneous medium. Simple calculation indicated that $10^{-9} \mathrm{~A} / \mathrm{cm}^{2}$, which is compatible with laboratory data (Hadjicontis and Mavromatou 1994), would suffice if the observation site and focal area are connected by a narrow conductive channel. One interesting feature of the selectivity map discovered by us (Uyeda et al. 1999) is that it changes with time: the EQ source mechanism in Kefallinia region changed from a strike-slip type to thrust type in late 1987 and this coincided with a shift in the sensitive site from PIR station to IOA station.

\subsubsection{The VAN-relation (how to predict $M$ )}

The other important discovery of the VAN group is the relationship among the focal distance, $r, \mathrm{M}$, and the observed intensity of SES, $\Delta \mathrm{V} / \mathrm{L}$, i. e.,

$$
\log (\Delta \mathrm{V} / \mathrm{L} \times \mathrm{r})=\mathrm{aM}+\mathrm{b},
$$

where a is constant $0.34-0.37$ and $\mathrm{b}$ is a site-dependent constant. $\Delta \mathrm{V} / \mathrm{L}$ is the potential change per unit length. Once the epicentral area is estimated from the selectivity rule, the expected value of $\mathrm{M}$ can be derived from the above formula, since $\Delta \mathrm{V} / \mathrm{L}$ and $\mathrm{r}$ are known. There have been some theoretical attempts to explain this relationship, in particular the value of the coefficient a (Surkov et al. 2002). 


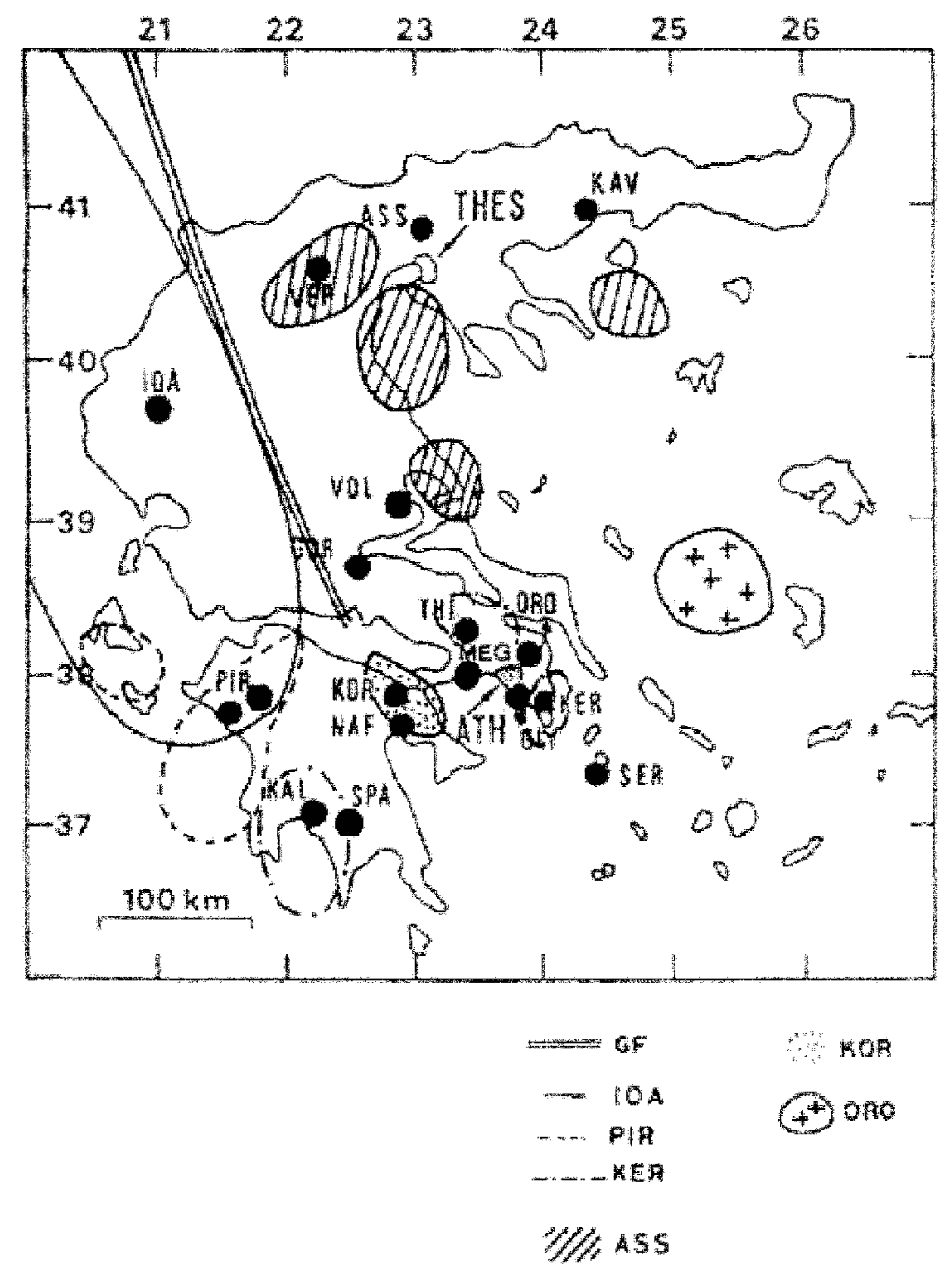

Fig. 5. The selectivity map of Ioannina station.

\subsubsection{Signal and Noise Discrimination}

To eliminate noise, they have developed a set of rules as follows:

1. Changes with magneto-telluric origin can be removed because they are recorded at all dipoles at all the stations simultaneously.

2. SES must appear simultaneously at all short and long dipoles at a station or stations concerned.

3. SES must satisfy the $\Delta \mathrm{V} / \mathrm{L}=$ constant relation for short dipoles in both EW and NS directions (in a homogeneous area).

4. The polarity and amplitude of SES of short and long dipoles must be compatible with the assumption that the source is distant compared with the dipole lengths: projection of SES 
vectors calculated from short dipoles on to long dipoles must have the same polarity and comparable amplitude with the observed change of the latter.

In order to examine the overall objectivity of these rules, we have made an exhaustive check of the original VAN data by performing the SES selection process independently of the VAN group (Nagao et al. 1996b). The total number of anomalous changes during 28.5 months (April 30, 1988 - Sept. 15, 1990), excluding the magneto-telluric ones, was over 3,000, but the number of changes that survived the rules 2, 3, and 4 was only 38, as shown in Fig. 6b, where the vertical axis is amplitude. During the study period, the VAN group issued 18 predictions based on SES observed at IOA station (Dologlou 1993; Varotsos et al. 1993b) as shown in Fig. 6a, where the vertical axis is predicted $\mathrm{Ms}(\mathrm{ATH})$. As they send their predictions only when the predicted Ms(ATH) is $\geq 5,18$ predictions in Fig. 6a should represent a subset of our 38 SES in Fig. 6b. In fact, 14 of the 18 VAN predictions were found to be based on the same changes that are included in the list of our SES. The 4 cases of disagreement are VAN prediction telegrams 13,16, 18 and 20. Despite a few cases of disagreement, it appears impressive that the two independent operations led to such a close overall match in picking up 14 common SES out of over 3,000 anomalous changes. It is important to note that many of the anomalous changes were, at first glance, indistinguishable from SES unless the above mentioned criteria are applied. In the last few years, several papers have appeared to criticize the VAN method based on actual field measurement data (Gruszow et al. 1996; Pham et al. 1998, 1999, 2002). They claim that some key SES, which were observed by VAN were noise of artificial origin. However, their arguments were ill founded in many ways. For instance, they noticed the similarities of the noise they observed and VAN's SES, and claimed that the latter might have also been noise. They seem to miss the point that noise and SES are often indistinguishable from their shapes and the rigorous application of the criteria mentioned above is needed to distinguish them. Furthermore, the VAN group has demonstrated that distant SES can be distinguished from noise by measuring the time difference of arrivals of electric and magnetic signals (Varotsos et al. 2003a; Uyeda and Tanaka 2004).

\subsubsection{The Performance of the VAN Method.}

Some critics assert that VAN's success rate is very low (e.g., Drakopoulos et al. 1993; Wyss and Allmann 1996; Mulargia and Gasperini 1992). It is striking because the same data and the same success/failure criteria are given to every assessor. Several reasons are conceivable. Frequent confusion is on the lead times for different types of signals. The assessors are advised to be careful not to deny success by simply applying wrong criteria. There are confusions in $\mathrm{M}$ scales. The VAN group has been using Ms (ATH) scale for their predictions. Unfortunately, however, Ms (ATH) sounds like a surface wave $M$ which it is not. Mixed use of different M scales can lead to wrong conclusions. The other origin of discord is concerned with the difference in the number of EQs that should be predicted. The VAN group states that their targets are $\mathrm{Ms}(\mathrm{ATH}) \geq 5.0 \mathrm{EQs}$ and their permissible error range in $\mathrm{M}$ is 0.7 . If the predicted $\mathrm{Ms}$ (ATH) was 5.0 and the actual Ms (ATH) was 4.3 , that prediction is naturally scored as successful. The alarm rate in this case, however, remains the number of successfully predicted $\mathrm{Ms}(\mathrm{ATH})$ $\geq 5.0 \mathrm{EQs} /$ the total number of $\mathrm{Ms}(\mathrm{ATH}) \geq 5.0 \mathrm{EQs}$. Some assessors, however, contend that 
(a)

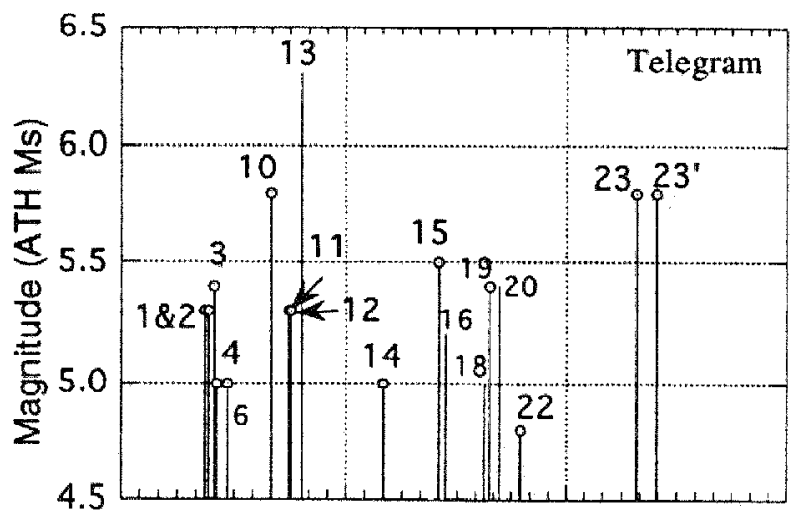

(b)

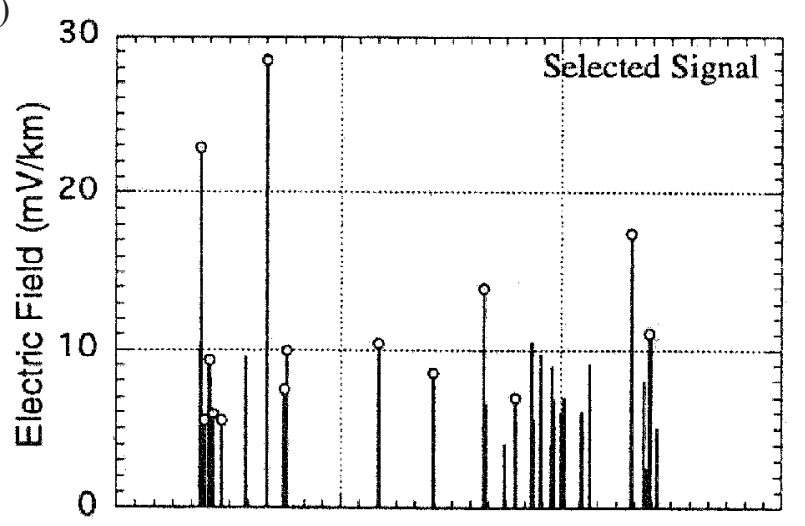

Fig. 6. (a) Top figure: all the 18 VAN predictions issued on the basis of SES data from IOA during April 30, 1988 - September 15, 1990. Telegram \# are attached. (b). Bottom figure: All the 38 SES selected independently by us (Nagao et al. 1996). Small circles are attached to those which are common in (a) and (b).

the VAN in such a case should target all the $\mathrm{Ms}(\mathrm{ATH}) \geq 4.3 \mathrm{EQs}$ and the alarm rate should be (the number of successfully predicted $\mathrm{Ms}(\mathrm{ATH}) \geq 4.3 \mathrm{EQs}$ ) / [the total number of $\mathrm{Ms}(\mathrm{ATH})$ $\geq 4.3 \mathrm{EQs}]$. The latter definition is obviously unreasonable in the true sense of experimental error.

We have examined the VAN's performance using the less ambiguous M scale, i.e. mb given in USGS NEIC PDE (Uyeda 1998; Uyeda and Al-Damegh 1999; Uyeda and Meguro 2004). Out of $16 \mathrm{mb} \geq 5.5 \mathrm{EQs}$ which occurred in the region (Fig. 7a) during Jan. 1, 1984 - Jan. $1,2004,13$ were predicted. After the prediction of three EQs in 1995, there were no large EQs until another three $\mathrm{mb} \geq 5.5$ occurred in late 1997. It is remarkable that during the 2.5 -year of quiescence no prediction was issued for the area and two out of the three 1997 events were 
predicted remarkably well. Second, M dependence of alarm rate for the period Jan. 1, 1987 Dec. 31, 1995 was examined for $\mathrm{mb} \geq 4.0 \mathrm{EQs}$. The alarm rate was found to increase dramatically with $\mathrm{M}$ from ca. $10 \%$ for $\mathrm{mb} \geq 4.0 \mathrm{EQs}$ to almost $100 \%$ for $\mathrm{mb} \geq 6.0 \mathrm{EQs}$, virtually excluding the possibility of chance success (Fig. 7b).

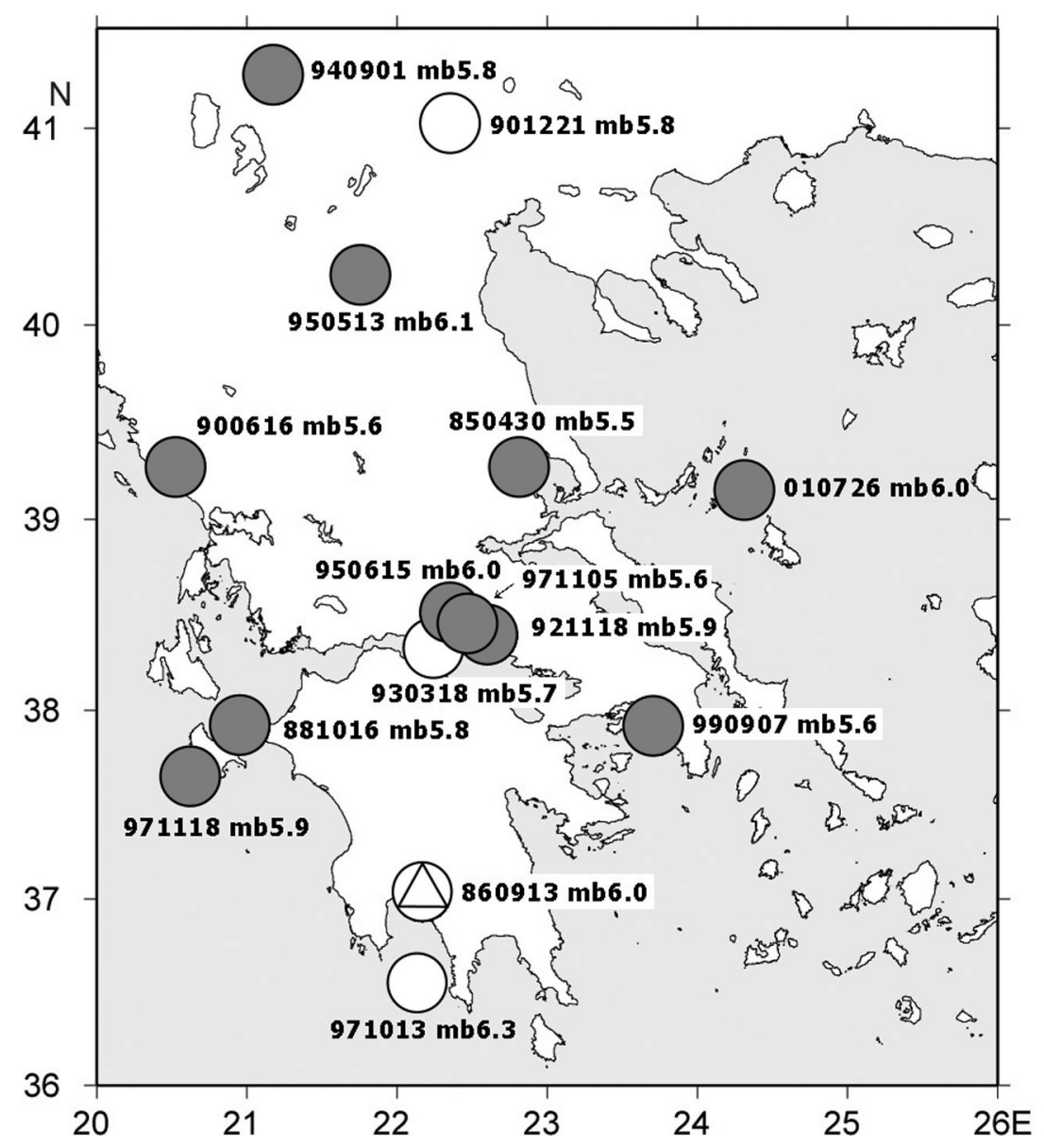

Fig. 7. (a) Performance of VAN prediction. All the earthquakes with USGS PDE magnitude larger than 5.5 for 1985-2003. Earthquakes are specified next to each circle. For example, 950513 mb 6.1 means year (1995), month (May), day $\left(13^{\text {th }}\right)$ and magnitude 6.1. The symbol mb is body wave magnitude. Shaded circles: "successfully" predicted. White circle with triangle: unsuccessfully predicted. White circles: missed. 


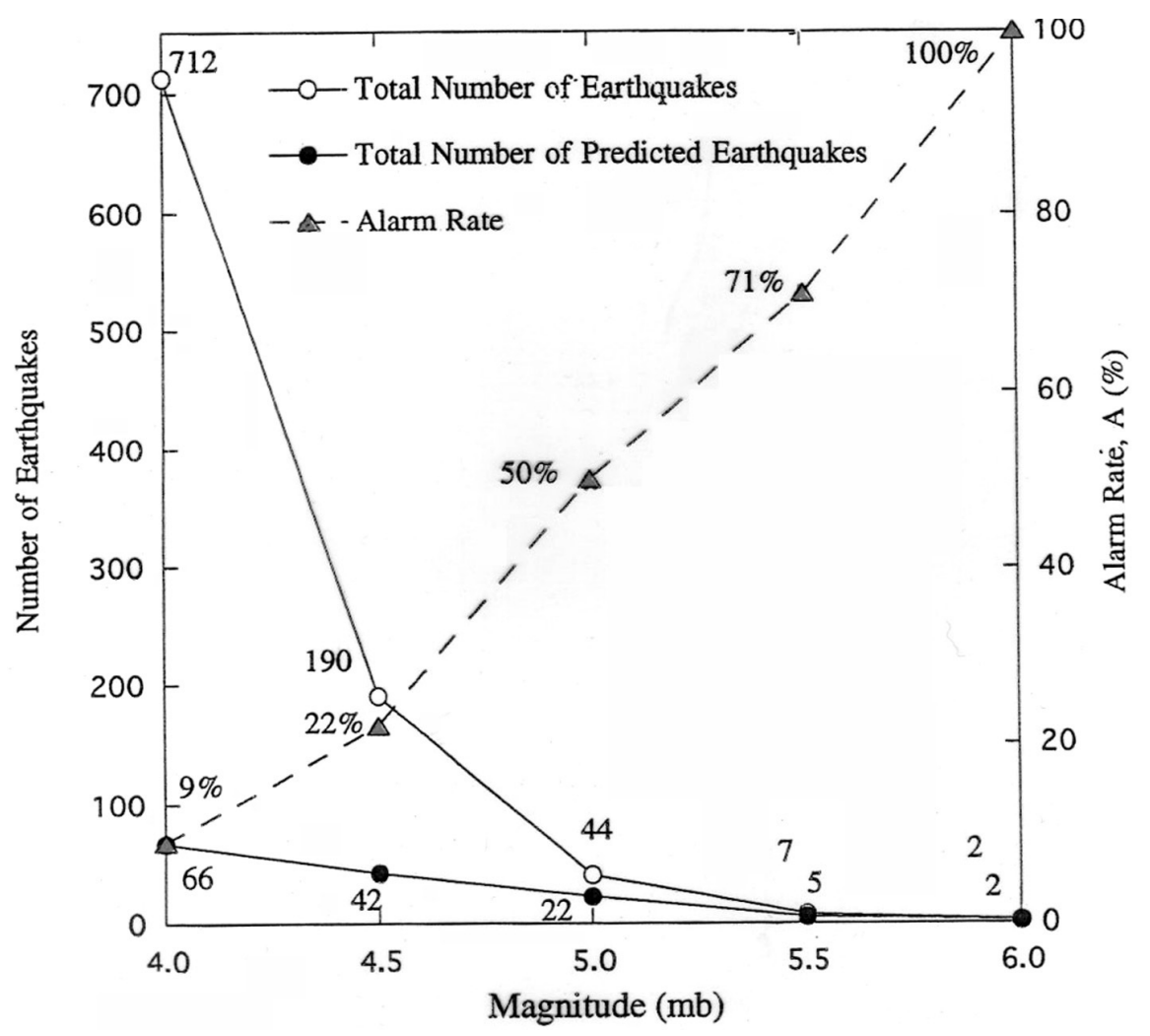

Fig. 7. (b) Diagram showing how the alarm rate A increases with the magnitude threshold. Open circle: total number of EQs with mb equal or greater than the threshold values on the abscissa for Jan. 1, 1987 - Dec. 31, 1995 and $19^{\circ}-25^{\circ} \mathrm{E}, 36^{\circ}-42^{\circ} \mathrm{N}$. Filled circle: total number of successfully predicted EQs. Triangles are their ratio, namely the alarm rate A.

\subsection{Physics of the VAN Method}

Here, there are two important problems. Firstly, is how the signals are generated. In this area, there are two major candidate model mechanisms. In one class of models, solids (the earth for that matter) emit electric current before fracture as explained in (e.g., Varotsos and Alexopoulos 1986; Lazarus 1993; Slifkin 1996; Lazarus 1996; Hadjicontis and Mavromatou 1996; Varotsos et al. 1996a), while the other model attributes the origin of the currents to the electrokinetic effect (Dobrovolsky et al. 1989; Gershenzon and Gokhberg 1993; Surkov et al. 2002).

The second important problem in the VAN method is how SES is selectively transmitted from the source to sensitive sites hundreds of km away, namely the physical and geological nature of current conduit(s) and what makes a site sensitive. 


\subsubsection{Solid State Processes}

\subsection{1a. Pressure stimulated currents}

An SES-generation model by pressure-stimulated currents (PSC) was proposed by Varotsos and Alexopoulos (1986). Their model is based on the physics of the point defects in solids. The impurities and vacancies have excessive and opposite-sign effective charges, respectively, and form local electric dipoles. The directions of the local electric dipoles without an external electric field randomly distribute. However, if there is an external electric field caused, for example, by piezo-electric effects in rocks during the stress accumulation of the pre-seismic stage, the direction of the electric dipoles aligns with that of the electric field by migration of impurities. This is a typical thermally activated process, where the relaxation time for the reorientation of the dipole is given by:

$$
\tau=\frac{1}{\lambda v} \exp \left(\frac{g^{m, b}}{k T}\right),
$$

where $\lambda$ is the number of jumpable and neighboring paths for the migration, $v$ is the attempt frequency, $k$ is Boltzmann's constant, $T$ is the temperature and $g^{m, b}$ is Gibbs's free energy for the migration. If $\tau$ is much longer than the duration of observation, no re-orientation takes place. Clearly, the relaxation time is shorter for higher temperature. But, more importantly, it can vary with pressure if $g^{m, b}$ depends on the pressure $P$. Therefore, on the external pressure increase, the relaxation time can decrease. When a solid is under the initial pressure $P_{0}$, the relaxation time may be very long. As the pressure increases, the relaxation time becomes gradually smaller. Then, when the pressure reaches a critical value $P_{c r}$, the relaxation time becomes sufficiently small. The electric dipoles align from the initial random orientation into the external electric field direction. Consequently, a transient electric signal is emitted. When the pressure still continues to increase, the pressure finally reaches the fracture stress $P_{f r}$ (Fig. 8). Therefore, the emission of this signal can be considered as a precursor to the fracture of a solid.

\subsection{1b. Charged Dislocations Mechanism}

Slifkin (1996) suggested that charged dislocations produce a large-scale electric dipole when the stress changes abruptly. Edge dislocations are often charged so that Debye - screening occurs around the edge dislocations by effective opposite-sign charges of lattice vacancies and impurities. If there are sudden stress changes, the dislocations quickly respond to it. They may not move through large distances, but bow out between pinning points as shown in Fig. 9. However the screening charges cannot quickly respond to the stress changes because it requires the motion of ions. Therefore, an electric dipole is produced by each bowed edge dislocation loop. The electric dipole moment is parallel to the slip plane and perpendicular to the dislocation line. A number of small electric dipoles make a bulk electric polarization because 


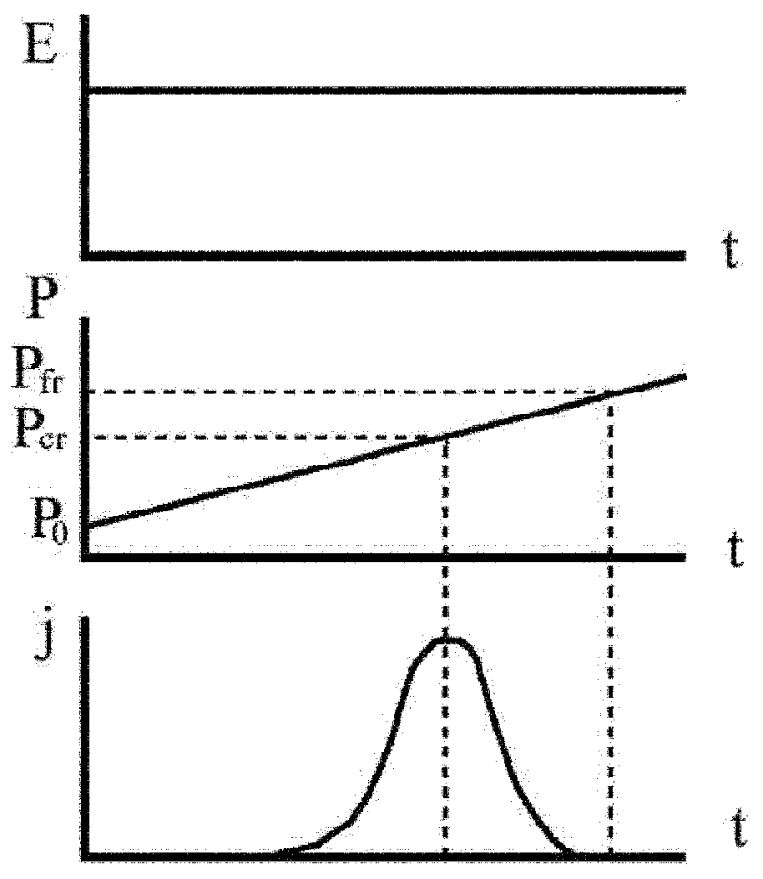

Fig. 8. The pressure stimulated current $i$ occurs at a critical pressure $P_{c r}$ under the external electric field $E . P_{f r}$ is the fracture pressure.

the directions of the participating dislocations are almost the same. Slifkin proceeded to show that the magnitude of the electric field produced by this mechanism in the real earth may be of the right order for the SES. An experiment reported by Hadjicontis and Mavromatou (1996) supported Slifkin theory.

\subsection{1c. Phase Transition Mechanism}

Lazarus (1996) suggested a phase transition mechanism. It was assumed that a dehydration phase change takes place near the fault by increasing stress. The compression of the lattice by this phase transition would cause large-scale deformation of the surrounding medium, which involves motion of lattice defects, namely dislocations as Slifkin suggested. The water expelled by dehydration diffuses to the interface at the fault and lubricates the fault to cause earthquakes. Lazarus' model can explain the time difference between the SES generation and the EQ occurrence at least qualitatively.

\subsection{1d. Stress induced electric signals in ionic crystals}

Nowick (1996) reviewed the early experimental studies (Fischbach and Nowick 1955, 1958) related with electrical phenomena in ionic crystals. In their experiment, a charge flow 


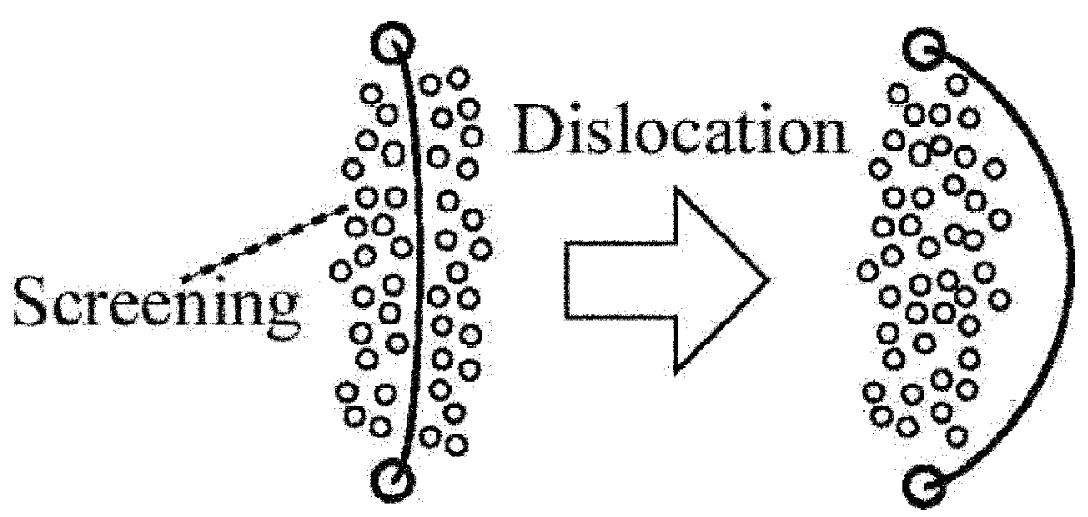

Fig. 9. Diagram showing electric dipole production by a dislocation.

was observed without an applied external electric field, when the crystals are deformed. The direction of the transient current is solely determined by the stress gradient. This deformation-induced current is observed even with an opposing applied electric field of the order of $\sim 10^{5} \mathrm{~V} \mathrm{~m}^{-1}$. Therefore, the charge flow is a current flow and not a voltsage effect. It may be expected that such a deformation-induced charge flow occurs around the future focal area before the final rupture.

\subsubsection{Electrokinetic Effect}

Electrokinsetic effect is also a strong candidate for the origin of SES. The effect, better known than the solid-state mechanisms mentioned above is caused by the presence of an electric double layer formed at the solid-liquid interface. The double layer consists of ions anchored to the solid phase, with an equivalent amount of ionic charge of the opposite sign distributed in the liquid phase near the boundary. When the fluid in such a system moves due to a pressure gradient, the charges in the fluid are transported in the direction of fluid motion, resulting in an electric current.

For a flow in a circular tube of radius $m$, the electric current density $\mathbf{i}\left(\right.$ in $\left.\mathrm{A} / \mathrm{m}^{2}\right)$ and the fluid volume flux $\mathbf{j}$ (i.e., flow velocity, in $\mathrm{m} / \mathrm{s}$ ) are described by the following relations (e.g., Pride 1994);

$$
\begin{aligned}
& \mathbf{i}=-\left(\kappa+\frac{2 \kappa_{s}}{\mathrm{~m}}\right) \operatorname{grad} \phi+\frac{\varepsilon \zeta}{\mu} \operatorname{grad} P_{p}, \\
& \mathbf{j}=\frac{\varepsilon \zeta}{\mu} \operatorname{grad} \phi-\frac{m^{2}}{8 \mu} \operatorname{grad} P_{p},
\end{aligned}
$$


where $\kappa$ and $\kappa_{s}$ are the electrical bulk and surface conductivities, $\varepsilon$ is the dielectric constant of the fluid, $\xi$ is the so-called zeta potential (the potential at the slipping plane near the boundary), $\mu$ is the viscosity of the fluid, $P_{p}$ is the pressure of the fluid, and $\phi$ is the streaming potential. The first term of (2-2-12) represents Ohm's law and the second term can be intuitively understood by considering the product of charge density (proportional to $\varepsilon \zeta$ ) and flow velocity of the viscous fluid (proportional to $\operatorname{grad} P_{p} / \mu$ ). To apply this basic theory to the porous media of the real world, such as subsurface flow in an oil reservoir and geothermal areas, models such as the capillary model, have been developed.

Electrokinetic phenomena are applicable in many geophysical research areas, including monitoring subsurface flows in oil reservoirs and in geothermal areas, and monitoring the activity of volcanoes. Mizutani et al. (1976) first proposed a model in which during the dilatancy stage, which is assumed to precede earthquakes, pore pressure in the dilatant region decreases and water flows into this region from the surrounding area, generating electric and magnetic precursors to earthquakes due to electrokinetic effects. Since then, many models have been proposed (e.g., Corwin and Morrison 1977; Fitterman 1981; Revil et al. 1999; Ishido and Pritchett 1999). In laboratory experiments, the zeta potential and the streaming potential coefficients were measured for crushed rock (e.g., Ishido and Mizutani 1981; Massenet and Ngoc 1985; Morgan et al. 1989; Lorne et al. 1999a) and for natural intact rock (e.g., Jouniaux and Pozzi 1995a). Some data have become available on electric signals due to electrokinetic effects during rock deformation up to failure using triaxial apparatus (Jouniaux and Pozzi 1995b; Yoshida et al. 1998; Lorne et al. 1999b). So far many geophysicists have estimated the magnitude of electromagnetic signals due to the electrokinetic effect. These estimates range widely due to the large number of poorly constrained parameters. Fedorov et al.(2001) indicated that the expected magnitude of seismo-EM signals in ULF band from an elementary electrokinetic source may reach the detection level only for a favorable set of crustal parameters.

\subsubsection{Transmission of Seismic Electric Signals (SES)}

The mechanism of SES transmission in the crust is one of the most important issues in order to understand electric and magnetic phenomena related to EQs. This section provides an outline of a conductive channel model which the VAN group has proposed.

Many arguments regarding SES transmission pathways have focused on the following two points:

1) Why is it that SESs can be observed so far away from an epicenter?

2) Why is it that SESs can be observed at only selected sites?

The first question naturally arises when a homogeneous structure in the crust is assumed. It was indicated earlier that unreasonable values of current source become necessary under a homogeneous medium in order to explain the typical SES amplitude (Bernard 1992; Utada 1993). We cannot give any reasonable explanation to the second question on the assumption that the resistivity of the crust has a uniform or layered structure. Therefore, some models including inhomogeneous structures should be invoked for this problem. 


\section{Conductive channel model}

The VAN group proposed a plausible model to explain the transmission (e.g., Varotsos and Alexopoulos 1986; Varotsos et al. 1993a). The model consisted of two horizontal resistive layers and a highly conductive channel embedded within the lower layer. According to their model, electric signals emitted from the current dipole are transmitted through the conductive channel to a point of the surface close to the upper end of the channel. Furthermore, the electric field observed there is intensified to become much larger than that produced at the same position in a homogeneous medium. They investigated this model in great detail by analytical (Vsrotsos et al. 1998) and numerical (Sarlis et al. 1999) methods and demonstrated that SESs become indeed detectable at long distance selected locations. The remaining problem would be to find out whether such a heterogeneous structure really exist or not.

\section{3. Recent Progress in VAN: "The natural time"}

Varotsos et al. (2002, $2003 \mathrm{a}, \mathrm{b})$ have proposed a new concept on the time domain in order to obtain a deeper physical insight on the relationship between SES activity and associated EQs. The new time domain is called "natural time" and is supposed to have possibilities of application to various fields of complex systems, including bio- or medical ones. In the natural time domain, time proceeds with events. In other words, if there is no event, time does not proceed. The natural time $\chi_{\mathrm{k}}=\mathrm{k} / \mathrm{N}$ serves as an index for the occurrence of the k-th event in a time series composed of $\mathrm{N}$ events such as SES activity and associated seismicity. Therefore, it is always between zero and one. Figure 10a illustrates how the original time series of SES activities were transformed to natural time domain. The weight of the k-th event is represented by the height of the bar which is the duration $\mathrm{Q}_{\mathrm{K}}$. It was found that the power spectra of the new time series $\left(\chi_{\mathrm{k}}, \mathrm{Q}_{\mathrm{K}}\right)$ for all the studied SES activities shown in Fig.10a were almost identical with each other. It was also shown that their power spectra were the same as the theoretically expected power spectrum of signals emitted from a system in a dynamically critical state. This supported the original idea of the VAN group that SES is emitted when the stress in the earth's crust reaches a critical state as mentioned earlier. Then, they proceeded to perform similar analysis on the seismic events after the SES activity. In this case, instead of duration $\mathrm{Q}_{\mathrm{K}}$, the seismic moment value, $\mathrm{M}_{0}$, was adopted as the weight of each event. Keeping the natural time zero at the initiation time of the SES activity, they started the calculation of power spectrum in natural time with $\mathrm{N}=6$. Repeating the calculation as the number of events, $\mathrm{N}$, increased, they discovered that the power spectrum, which was different from that of the SES activity when $\mathrm{N}$ is small, became identical with the latter when $\mathrm{N}$ reaches some number, less than 40 or so, as seen Fig. 10b and, moreover, the expected main shock occurred in a few days after the power spectrum coincidence. They have found this also for all of the cases they examined. If this holds universally, time prediction of the VAN method will be much improved to a few days. Moreover, these findings seem to indicate an important aspect in the earthquake physics that not only SES activity but also seismicity is a critical phenomena. Readers are advised to see their original papers for details. 
(a)

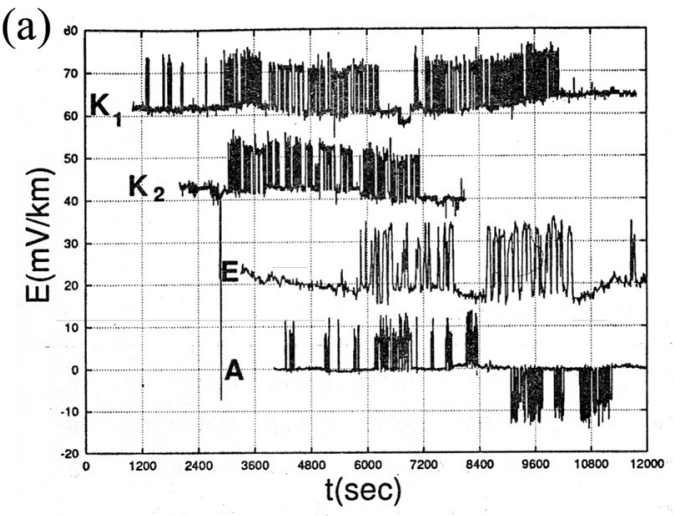

(b)

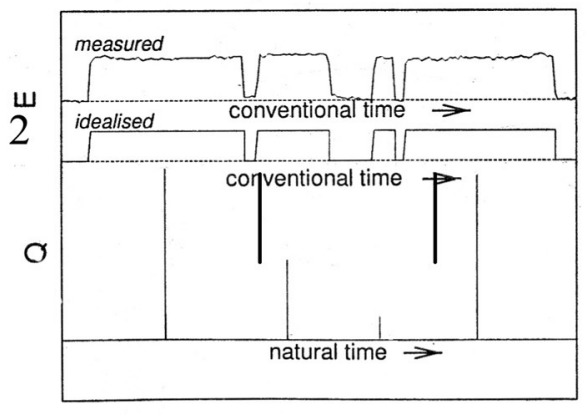

(c)
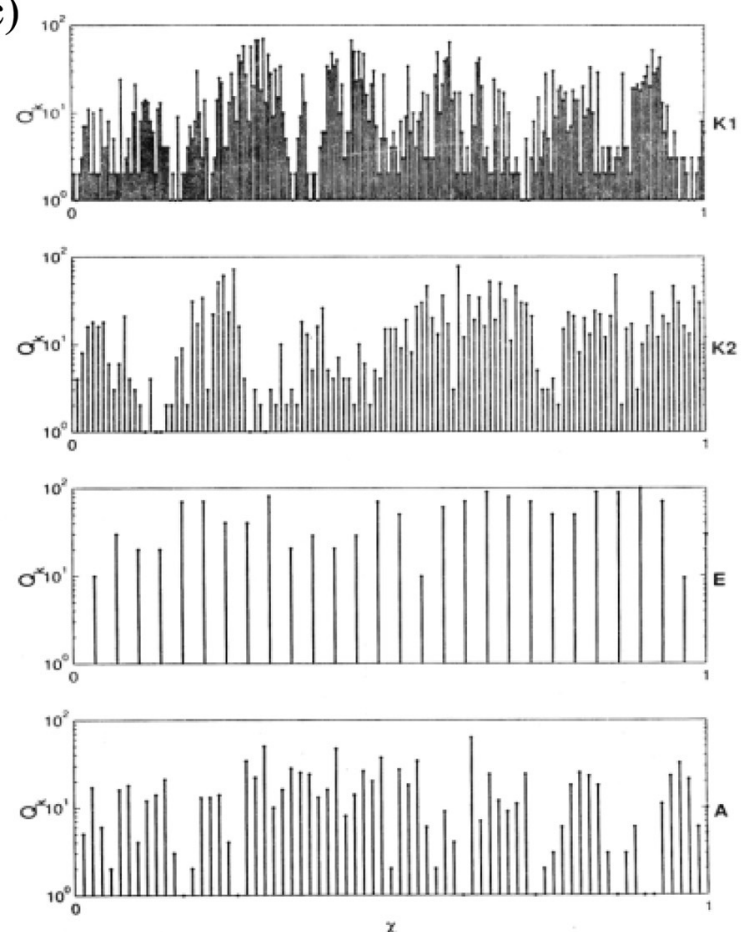

Fig. 10a. (a) Four examples of SES activities $\left(\mathrm{K}_{1}, \mathrm{~K}_{2}, \mathrm{E}\right.$ and $\mathrm{A}$ as recorded. (b) The method to transform into time series in natural time. SES signals are placed at equal intervals and given the weight proportional to their durations $\mathrm{Q}$. Thus the $\mathrm{k}$-th signal is placed at natural time $\chi_{\mathrm{k}}=\mathrm{k} / \mathrm{N}, \mathrm{N}$ being the total number of signals, with a height $\mathrm{Qk}$. (c) The same SES activities $\left(\mathrm{K}_{1}, \mathrm{~K}_{2}, \mathrm{E}\right.$ and $\left.\mathrm{A}\right)$ in natural time.

\section{RIKEN INTERNATIONAL FRONTIER RESEARCH ON EARTHQUAKE (IFREQ)}

\section{1. Monitoring System}

IFREQ started in October 1996, with its headquarters at the Earthquake Prediction Research Center (EPRC), Tokai University, Shimizu. Since 2001, IFREQ has also been in operation at Chiba University. The project started with constructing stations for VAN-type monitoring geoelectric potential difference (GPD hereafter) and ULF geomagnetic variation throughout Japan. We took up ULF $(\sim 0.01 \mathrm{~Hz})$ geomagnetic variation monitoring as one of the two major sub-programs of IFREQ because pioneering work had already been achieved in this frequency range (Kopitenko et al. 1993; Fraser-Smith et al. 1990; Hayakawa et al. 1996). The ULF aspects of IFREO will be reported in an accompanying paper (Hattori et al. 2004). 
(a) Seismicity

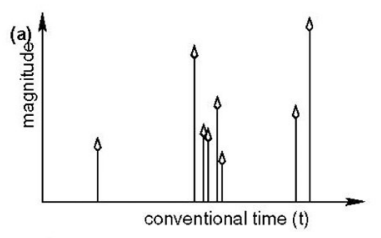

(b) Seismicity in natural time
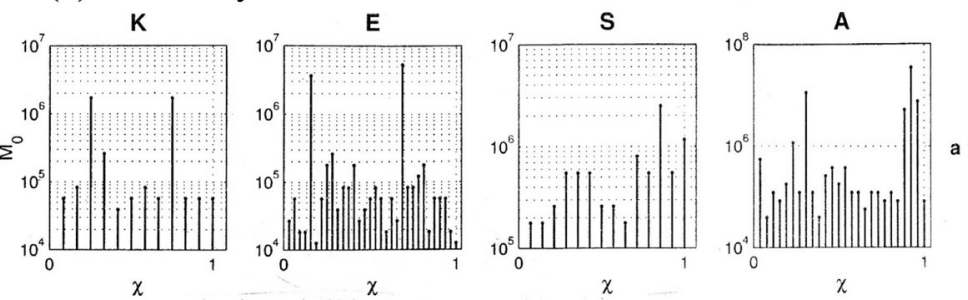

(c)
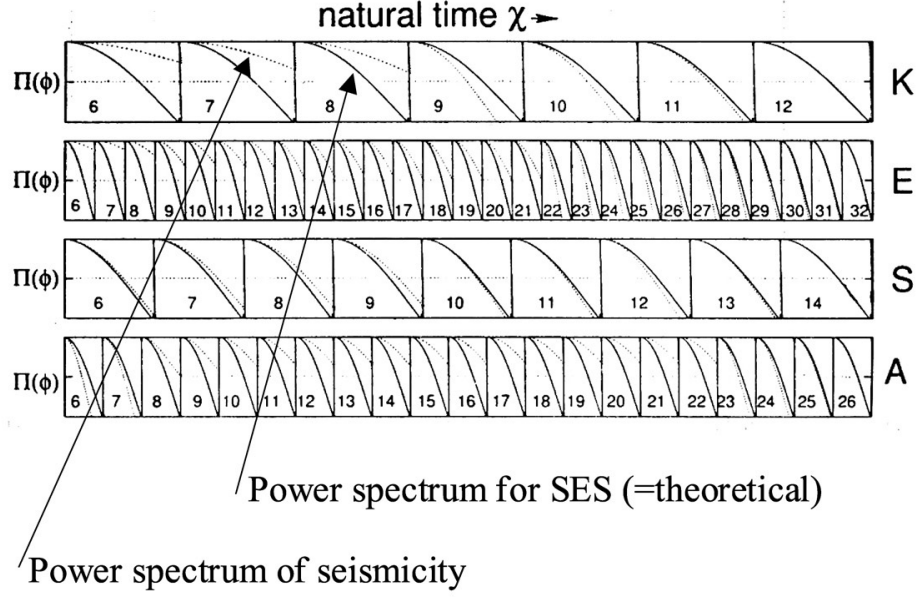

Fig. 10b. (a) Transformation of seismicity into natural time. The bar for the k-th earthquake at natural time $\chi_{\mathrm{k}}=\mathrm{k} / \mathrm{N}$ has height proportional to $\log \mathrm{M}_{0}$, representing its magnitude. (b) Natural time presentation of seismicity following the SES activity. (c) Power spectrum of seismicity before each major earthquake coincides with the power spectrum of SES activity after some number of seismic events.

In 2000, 40 GPD stations and 19 geomagnetic stations were in operation (14 of them were common stations, (Fig.11). Most of the GPD stations were equipped with short and long dipoles, whereas ULF magnetic stations had one of three types of 3-component magnetometers; i.e., torsion, induction and fluxgate types.

\subsection{Geoelectric Potential Difference (GPD) Changes:}

\subsubsection{Confirmation of the Existence of VAN-type Seismic Electric Signals (Uyeda et al. 2000)}

To remedy weaknesses in prior Japanese GPD monitoring that used only long ( 10 km) dipoles, IFREQ used both long and short $(\sim 0.1 \mathrm{~km})$ dipoles at its stations. This was helpful in discriminating local noise and signal from distant sources. The primary aim of the project was 
to detect SES. It was a risky campaign because: 1) many stations have to be tested for sensitivity as Greek experience indicated that only about $10 \%$ of trial sites were sensitive to SES, and 2) Japan is electrically far more noisy than Greece and available land is extremely limited due to population density. For example, much of the land is covered by networks of the worst kind of noise source namely DC driven railroads. However, the existence of VAN-type SES have been almost ascertained by this project.

SES have been recognized through applying the following criteria as rigorously as possible: 1) The ( $\Delta V / L)$ test for short dipoles and simultaneous appearance on short and long dipoles. 2) No such changes, which were not followed by EQs. Certitude of the precursory nature is variable depending on non-ideal situations in actual cases.

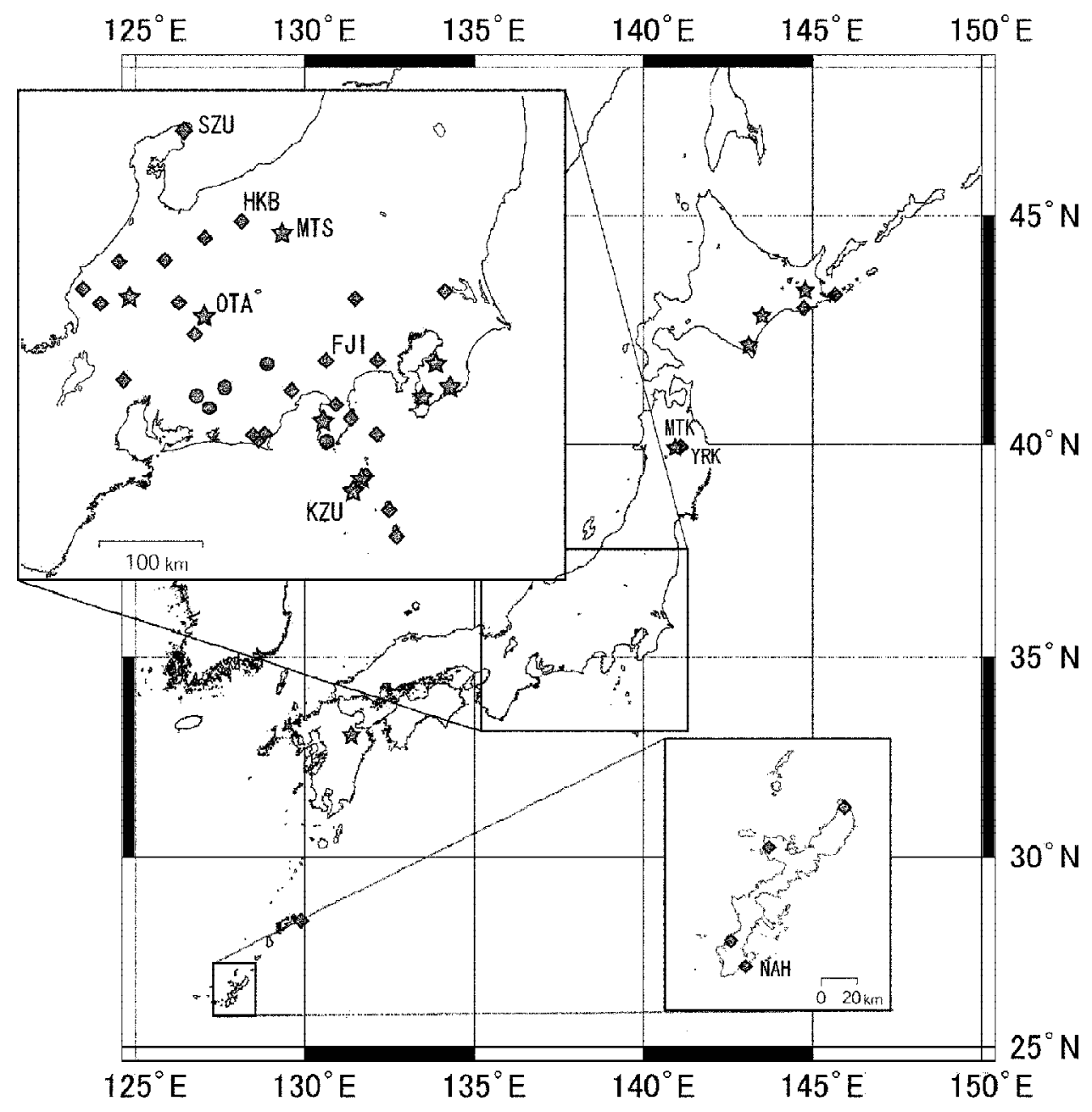

Fig.11. Distribution of GPD (filled diamonds), ULF magnetic (circles) and combined (stars) stations. Pre-IFREQ stations (NAH and SZU) are also shown. 


\section{2.1a. Near source SES}

GPD changes similar to VAN's SES have been observed before several EQs in Japan. Generally, they appeared 1 - 20 days before EQs and their duration and intensity were several minutes to one hour and $1-2 \mathrm{mV} / 100 \mathrm{~m}$. The changes appeared before five out of all six EQs with magnitude $\geq 5$ that occurred within $20 \mathrm{~km}$ of our quiet station during 1996-1999 (Compare Figs. 11 and 12). The only EQ which did not show SES among six was (EQ99/03/28), possibly representing the selectivity map of that island (see 4.2.2).

Examples of near source SES are:

M6.6 Off Noto Peninsula EQ93/02/07: A strong and long change on the SZU long dipole network lasted for 56 days until the EQ occurred at epicentral distance $r<10 \mathrm{~km}$. The change occurred at only one electrode closest to the epicenter. The change was similar to VAN's Gradual Variation of Electric Field (GVEF).

M5.3 EQ96/03/06: One hour long multi-peaked anomalous change at FJI (a train-noisy station) occurred 6 days before the EQ at $\mathrm{r}=15 \mathrm{~km}$. The change was clearly visualized by the so-called particle motion diagram (PMD) plot technique. Later in the observation period, there were two electric changes with 2-3 minute duration, satisfying $\Delta \mathrm{V} / \mathrm{L}$ test but followed by no EQs. Their source is unknown.

M5.1 EQ97/05/22: This EQ occurred 7 km east of Kozu-shima Island. On 97/05/20 and 97/ $05 / 21$, one and two days before the EQ, there were clear SES like signals at KZU long and short dipole station on this electrically quiet island. During the observation period, there were numerous smaller EQs in the area and numerous SES like signals, correspondence of which may demonstrate a new type selectivity map of KZU station (see 4.2.2).

M6.1 EQ98/09/03: Two weeks before the EQ, at YRK long and short dipole site $(r=13 \mathrm{~km})$ of Mt. Iwate Network (Fig. 3A), a remarkable SES (Fig. 13B) was recorded in the early morning $(03: 35 \mathrm{LT})$. The signal was not recorded at nearby MTK short dipole site located in the geothermal area, perhaps reflecting the complex hydroelectrical setting. Mt. Iwate is an active volcano. The recorded SES is the only change and EQ98/09/03 is the only $\mathrm{M}>5 \mathrm{EQ}$ in the wide area of Fig. 13A up to the present, making this time correlation highly convincing.

\subsection{1b. Distant Source SES}

SES like signals detected at greater epicentral distances (up to $75 \mathrm{~km}$ ) are:

M6.0 EQ88/01/24: A multi-peaked SES like signal at NAH long dipole network (Okinawa) appeared six days before this EQ at about $50 \mathrm{~km}$ NE of the network. During the observation period (1987/09/25 - 1991/07/01), there were no other M > 5 EQ nor other similar electrical changes around the network.

M4.7 EQ990128: At 01:30 (LT) of 1999/01/17, three widely separated stations, MTS, HKB 


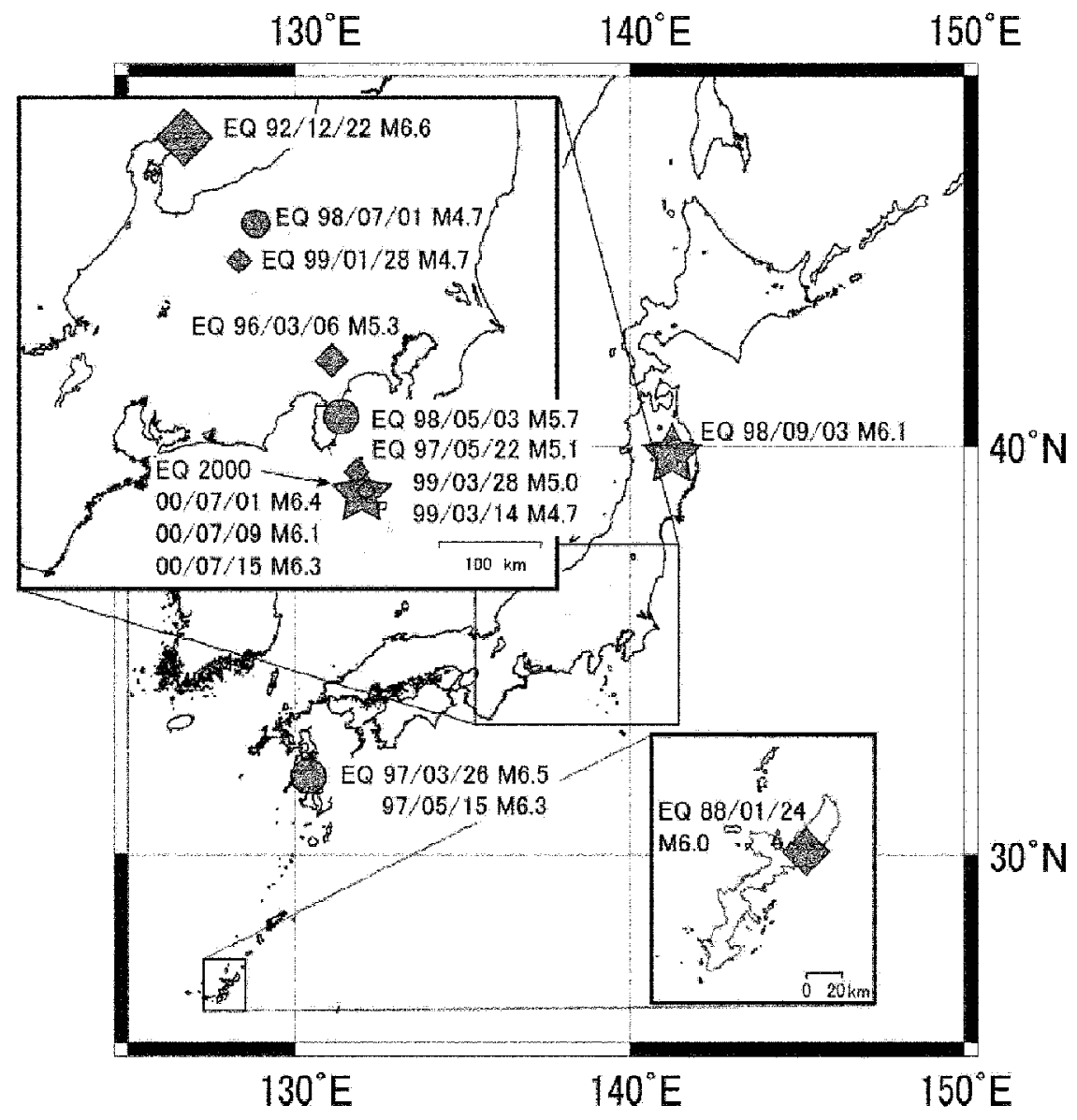

Fig. 12. Distribution of $\mathrm{M} \geq 5$ earthquakes with pre-seismic signals up to March 1999. Diamonds and circles show earthquakes with observed pre-seismic electric signals and ULF magnetic signals, respectively. Stars show earthquakes with both electric and magnetic signatures. EQ 98/09/03 M6.1 means M6.1 earthquake which occurred on September 3, 1998.

and OTA in Nagano Prefecture, Central Japan (Fig. 14), recorded a simultaneous change lasting 27 minutes. After 11 days, a swarm of activity of more than 30 shocks, with the main shock M4.7 EQ99/01/28, occurred in the middle of the triangular area formed by the three stations. This event was unique in that simultaneous change occurred at three widely separated stations, and that the epicentral distances to stations were large with the largest being $75 \mathrm{~km}$ (OTA). Finally, there were no signals at the other stations such as OTW, KWI, HGW and TKC which have similar epicentral distances (Fig. 14A). If the observed change was really the SES of EQ99/01/28, the case could be an example of the VAN's "Selectivity" situation. On Nov. 10,2000 , there was another case of simultaneous change but without a following earthquake. 
(A)

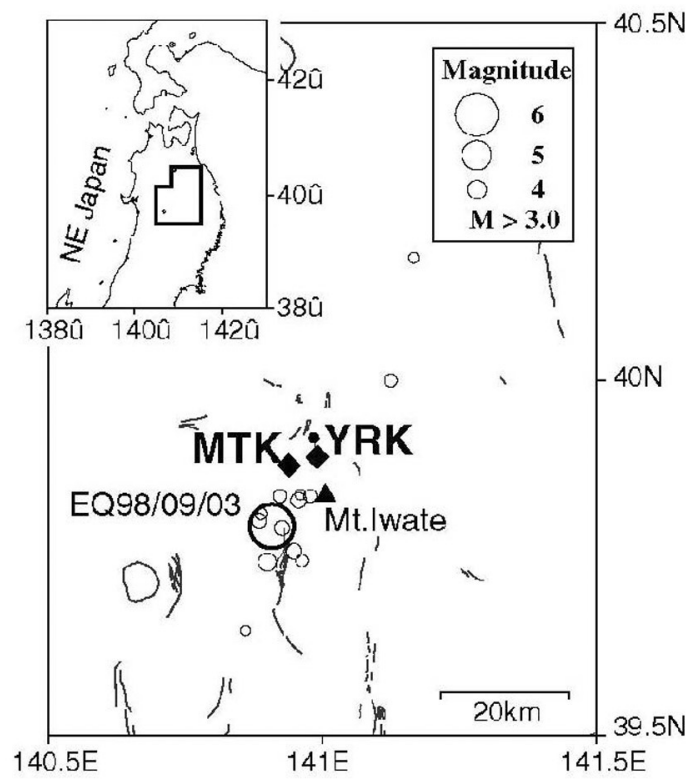

(B)

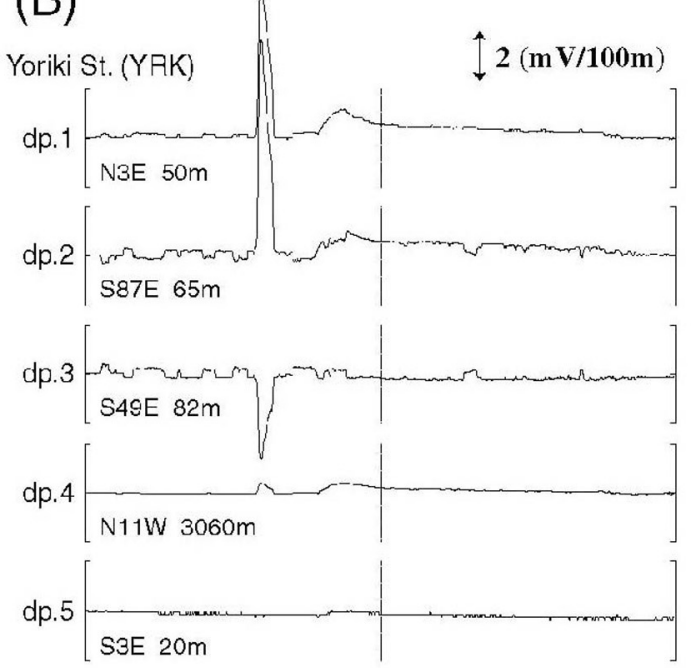

Matsukawa St. (MTK)

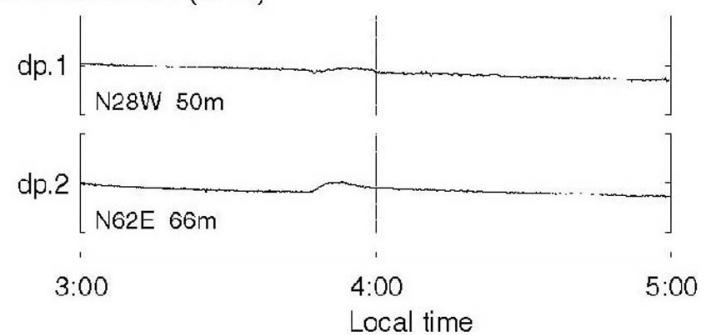

Fig.13. (A) Seismicity of Tohoku region (1998/06/28 - 1999/05/31) and sites YRK and MTK of Mt. Iwate Network. (B) Pre-seismic change recorded at YRK and MTK on 1998/08/20.

Although the signal was different in wave form (much shorter signals), this presents a problem regarding the repeatability of the phenomena.

\subsubsection{Possible New Type of Selectivity at KZU Station (Orihara et al. 2002)}

From 14 May 1997 to 30 Nov. 1999, there were 21 SES like signals and 26 M > 3 EQs within about $20 \mathrm{~km}$ of Kozu-shima Island. Although there was some ambiguity, the best possible signal-EQ correspondence indicates the existence of some systematic distribution of EQs of which SES were observed at KZU station. The one EQ for which no SES was observed (EQ99/03/28) in Fig. 12 was out of the sensitive sectors delineated in Fig. 5. This result seems to suggest that appearance/non-appearance of SES can be non-uniform even in such a small area, forming a new type of selectivity. Moreover, the polarity of probable SES shows a dis- 
(A)

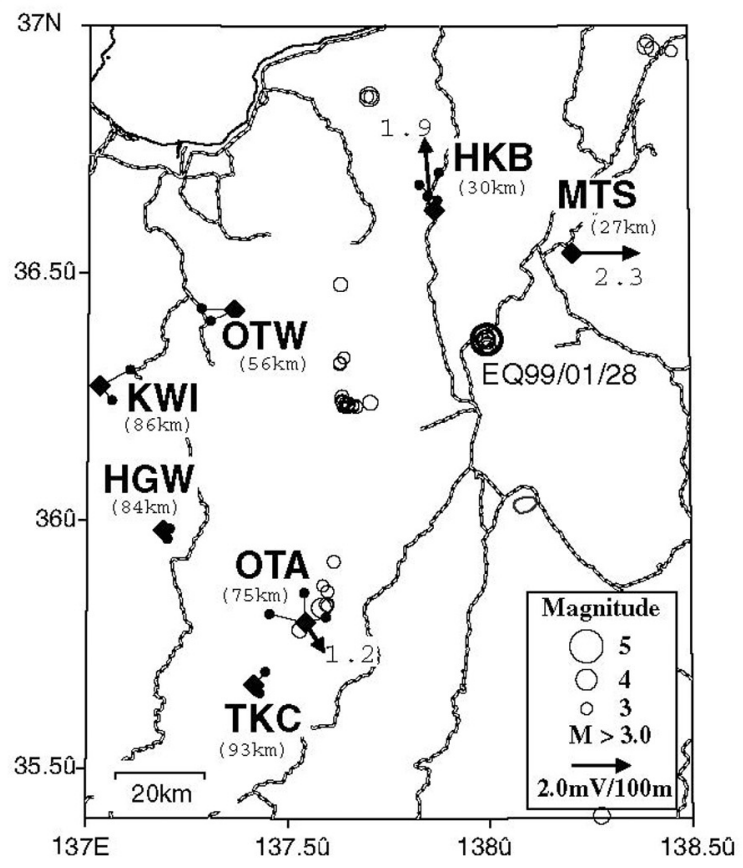

(B)

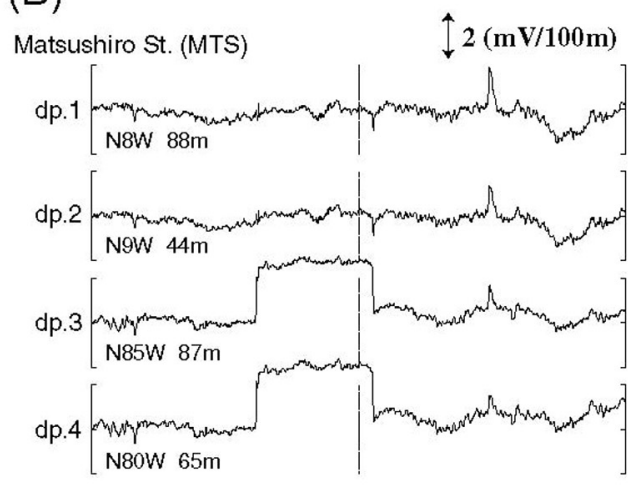

Hakuba St. (HKB)
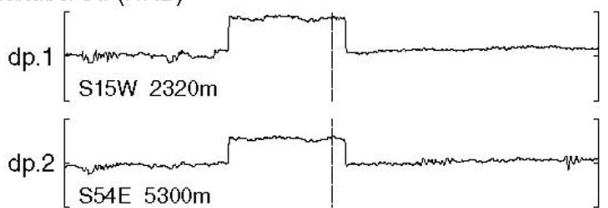

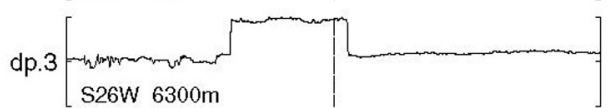

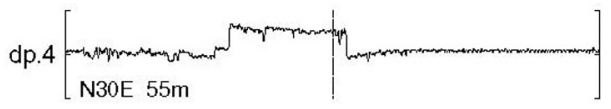

Outaki St. (OTA)

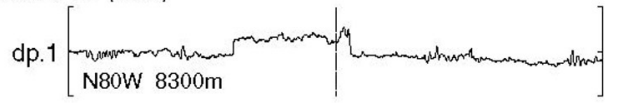

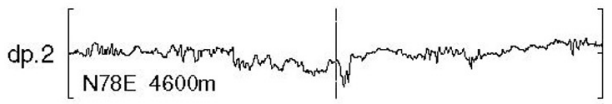
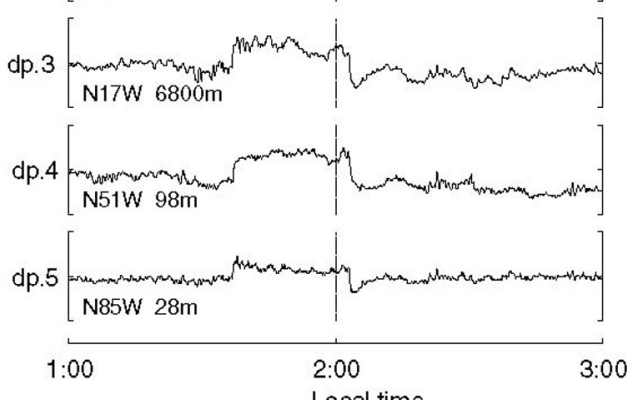

Fig. 14. (A) Distribution of stations and seismicity (1998/10/01 - 1999/05/31) in Central Japan. The arrow and number attached to MTS, HKB and OTA are directions of the change and epicentral distance. (B) The change simultaneously observed at the three stations. 
tinct distribution (Fig. 15). These features may be indicative of extreme heterogeneity of the subterranean electrical structure under the volcanic arc.

\subsubsection{Co-seismic Signals (Nagao et al. 2000)}

Co-seismic signals of GPD have been observed for many EQs. It has been often argued that if there are SES, stronger signals should occur at the time of an EQ. Our results prove that co-seismic signals do exist as shown in Fig. 16. Most of the EQs are actually the same EQs for which SES were observed (2.1). But they start with the arrival of seismic waves and not at the origin time of EQs. Their amplitude does not scale with the dipole length. Both facts indicate that the changes are local effects of passing seismic waves and not due to electric signals emitted from the seismic source. Observed changes contain two components: oscillatory and offset/decay. The former is synchronized with seismic waves, whereas the latter, with a rise time of a few seconds and a decay time of $0.1-1$ hour, is suspected to be related to EQ induced subsurface hydrological change. In both cases, the origin of electric potential variations may be electrokinetic.

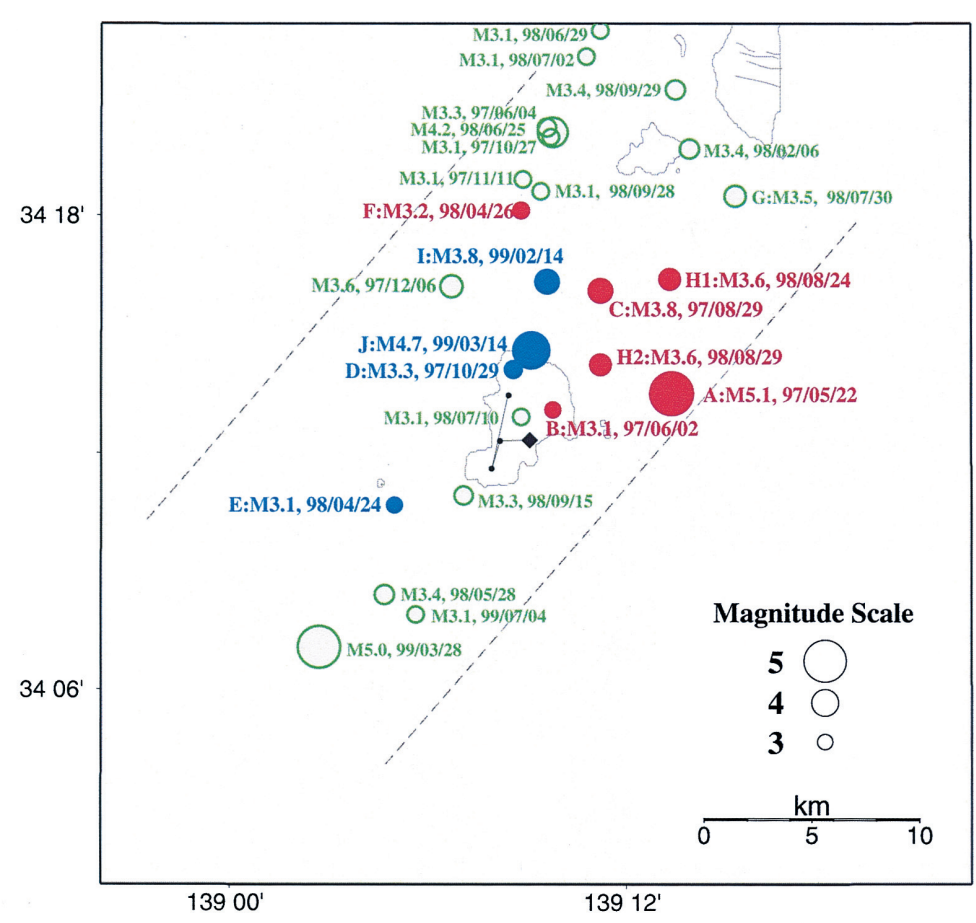

Fig. 15. Distribution of EQs around Kozu-shima Island, showing a possible selectivity map. Red (blue) circles indicate positive (negative) SES. No SES was observed for Green circles. 

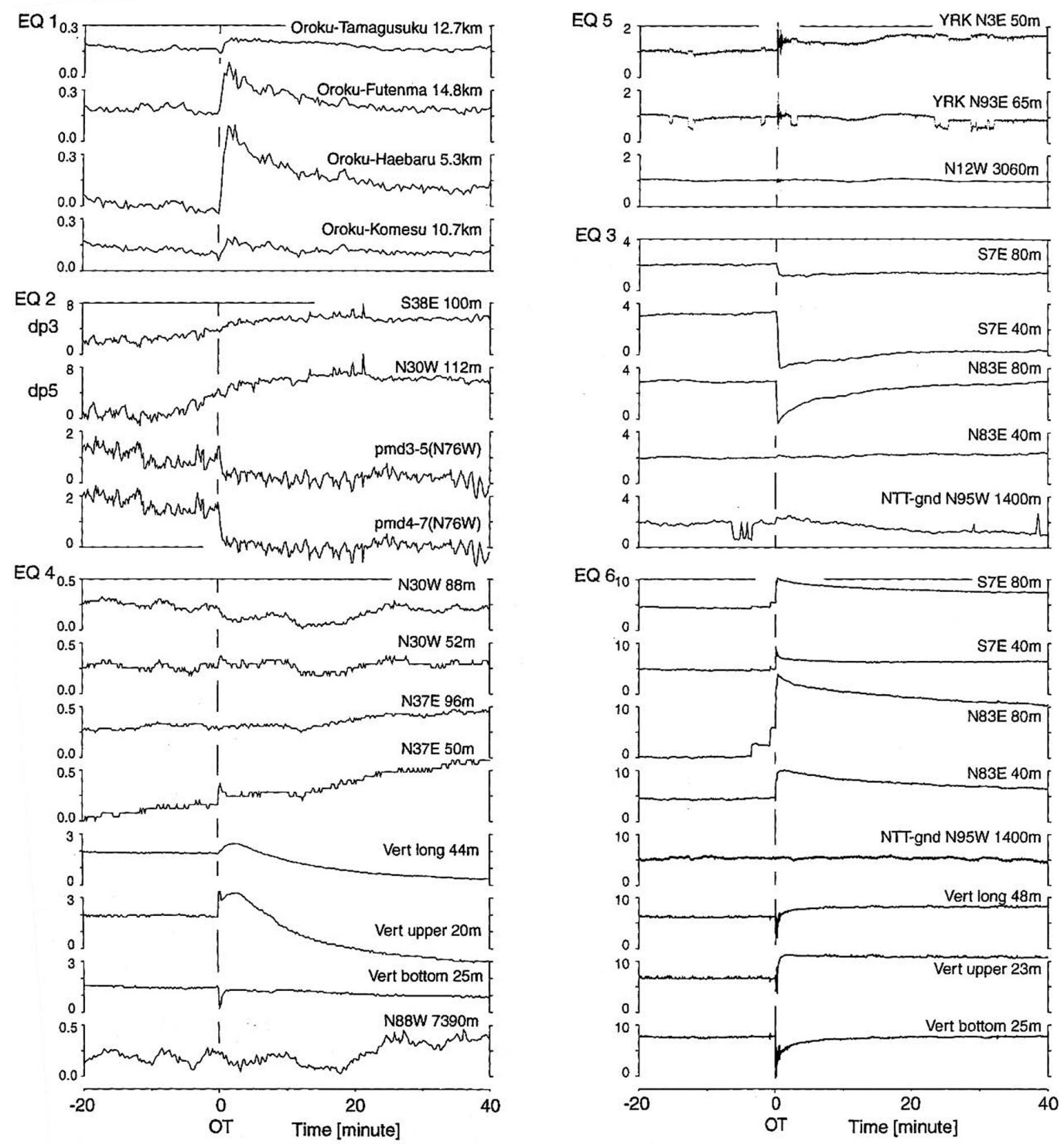

Fig. 16. One hour records of GPD in $\mathrm{mV} / 100 \mathrm{~m}$. OT: origin time EQ.

EQ1: M6.0 EQ88/01/24, NAH long dipoles with length attached to each curve.

EQ2: M5.3 EQ96/03/06, FJI short dipoles.

EQ3: M5.1 EQ97/05/22, KZU short and long dipoles.

EQ4: M4.7 EQ990128, OTA short and vertical dipoles. Note the distinct difference in the appearance of the signal on different dipoles.

EQ5: M6.1 EQ98/09/03, YRK short and long dipoles.

EQ6: M.4.7 EQ99/03/14, KZU short, long and vertical dipoles. 
We propose that the observed signals should be called co-seismic wave signals. The reason for not observing true co-seismic signals may be twofold. One is that true co-seismic signals generated at ruptures are in a much higher frequency range, so that they cannot be registered by usual GPD measurement $(0.1 \sim 1 \mathrm{~Hz}$ sampling $)$ and the other is that, even when a higher sampling rate is employed, the high frequency signals attenuate before reaching the receiver over a short distance in the earth (e.g., $0.5 \mathrm{~km}$ for $1 \mathrm{kHz}$ signal).

In 1997, clear co-seismic changes were also observed in Sumatra, Indonesia, at stations installed by IFREQ Indonesia-Japan cooperative research (Mogi et al. 2000).

\section{3. Other Related IFREQ Investigations}

\subsubsection{Electrokinetics at Rock Fracture (Yoshida et al. 1998; Yoshida 2001)}

Laboratory experiments on convection electric current at rock rupture was studied with a specially designed triaxial apparatus with an extremely slow strain rate $\left(10^{-10} / \mathrm{s}\right)$. It has been demonstrated that the convection current flowed before the main fracture, showing good correlation with the dilatancy rate and the water flow rate. The current density was about $1 \mathrm{~mA} / \mathrm{m}^{2}$ indicating that the electric current is caused by an electrokinetic effect due to the water flow associated with accelerating evolution of dilatancy before the fracture.

\subsubsection{Acoustic Emission before EQs (Gorbatikov et al. 2002)}

Facts with potentially extreme importance have been observed by cooperative research between Japan and Russia. Intense AE was recorded in a special tunnel inside a rocky mountain at a depth of about $100 \mathrm{~m}$ at Matsushiro Seismological Observatory, JMA. A sensitive 3component magneto-elastic receiver with a frequency response proportional to the cube of frequency, made in Russia, was used at four narrow bands of 30, 160, 500 and $1000 \mathrm{~Hz}$. During February to August, 1998, it was found AE was remarkably enhanced from about 12 hours before EQs. Most noticeable enhancement occurred for M.4.7 EQ98/07/01 ( $\mathrm{r}=24 \mathrm{~km})$, for which a ULF magnetic signature was also noticed. Sources of AE are supposed to be near the sensors because high frequency acoustic waves cannot propagate over such long distances as kilometers. This may provide some important clues to understanding the earthquake preparation process. Multi-station observations are needed for further studies.

\subsubsection{Precursory Phenomena Estimated from Seismicity}

Corresponding to laboratory experimental results that rock samples pass, before fracture, prognostic stages of quiescence, foreshock activation and clustering of $\mathrm{AE}$, field seismological observations also indicate similar stages before a strong EQ. IFREQ studied this type of precursory phenomena using algorithms such as M8 (Keilis-Borok and Kossobokov 1990) and RTL (Sobolev and Tyupkin 1997).

Huang et al. (2001) investigated the seismicity changes related to M7.2 EQ95/01/17 (Kobe EQ) by applying the R (Region) T (Time) L (Length) algorithm to JMA EQ catalog, and found that the RT parameters indicated a seismic quiescence starting in 1993 to bottoming in May 
1994. This quiescence was followed by an activation stage lasting for about seven months. The case was similar to other large EQs in Kamchatka and Hokkaido.

\section{RESEARCH IN WIDE FREQUENCY RANGES}

\subsection{Kobe EQ}

In Japan, several research groups have worked on EQ related EM phenomena since the early 1990's. At the time of the 1995 Kobe EQ, several groups witnessed anomalous EM phenomena in frequencies ranging from extremely low frequency (ELF; $10^{2}-10^{3} \mathrm{~Hz}$ ) to very high frequency (VHF; $\sim 10^{2} \mathrm{MHz}$ ) as shown in Fig. 17 (Nagao et al. 2002). Prominent preseismic peaks in the ELF, LF $(\sim 100 \mathrm{KHz})$ and $\mathrm{HF}(\sim 10 \mathrm{MHz})$ signals were observed about one week before the earthquake at different observation sites, some close to Kobe and some five hundred kilometers away. They were considered to be pre-seismic emissions from the focal zone, although there was a possibility that some records were affected by thunderstorm noise. Anomalous transmissions of man-made electromagnetic waves in very low frequencies (VLF; $10 \mathrm{KHz}$ ) and VHF bands were also detected for a few days before the EQ (third and second panels from bottom), indicating the possibility that the ionosphere above the focal zone was disturbed at the final stage of the seismogenic process. Encouraged by these results, seismo-EM research in Japan has become very active. IFREQ was one such research program.

\subsection{Electric and Magnetic Anomalies Associated with the 2000 Volcanic-seismic Activity in Izu Island Region}

A swarm of seismic activity started on June 26,2000 , simultaneously with volcanic activity on Miyake-jima Island. It quickly spread northwestward from the Miyake-jima Island to Toshima Island via Kozu-shima and Niijima Islands. Within the three month period of activity, more than 10,000 earthquakes ( $M \geq 0$ ), including five events with $M \geq 6$, were recorded (Fig. 18). We observed significant pre-seismic EM phenomena related to this swarm activity (Uyeda et al. 2002).

From about two months before the start of the volcanic-seismic activity, frequent anomalous changes in geoelectric potential difference began to be observed on one dipole (Wak-Air) on Niijima-island (Figs. 18 and 19). This disturbed state became more enhanced after June 26 and culminated before the first nearby large EQ (M6.4 EQ00/07/01) and appears to have lasted for about four months, although there was a period of interrupted monitoring due to power failure and instrument damage. Such a disturbed state was the first encountered since the beginning of monitoring in 1998. The reason why the anomalous changes were observed only at the Air-Wak dipole is not clear but it may be related to the fact that only the Wak area is covered by basalt, while the rest of the island consists entirely of rhyolite. Furthermore, the changes in the geoelectric potential difference were found fit well a power law superimposed by a log-periodic oscillation (Tanaka 2003). Thus, the changes in geoelectric potential difference are considered to be related to a critical phenomenon occurring on a fractal. 


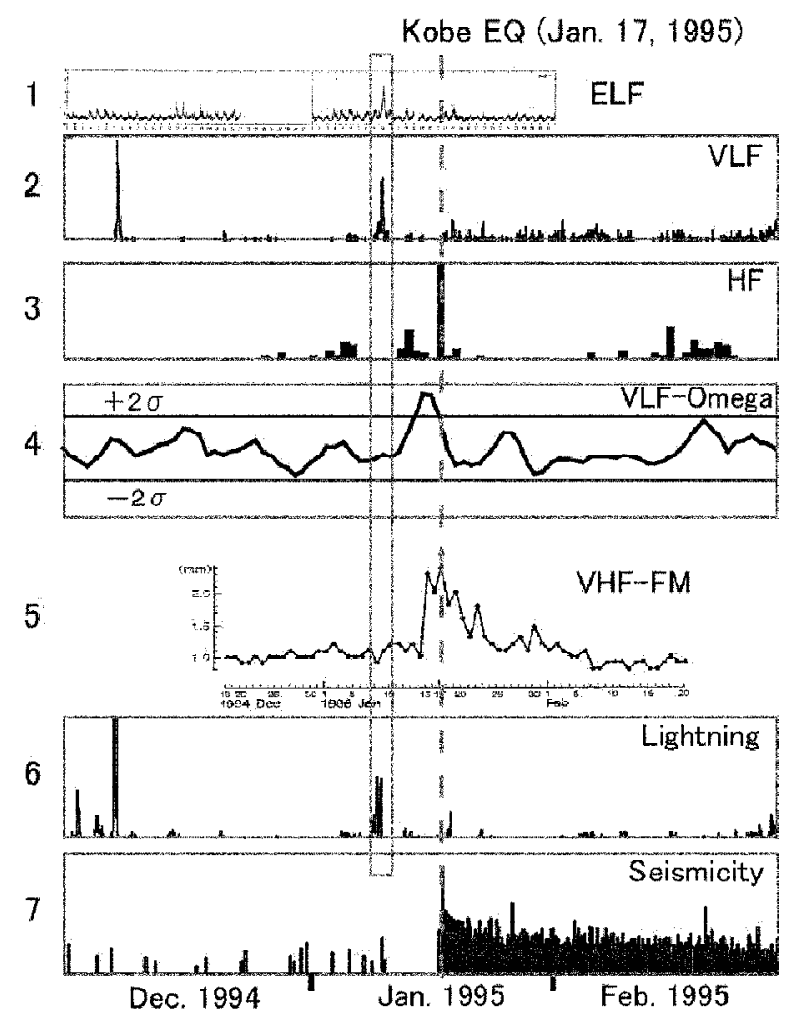

Fig. 17. Three month records around the Kobe EQ. See Nagao et al. 2002 for details. Panels 1 and 2 show EM noises in ELF (Hata 1994) and VLF (Fujinawa and Takahashi 1994) bands observed at stations several hundreds of $\mathrm{km}$ away from the epicenter. The peaks appeared about one week before the EQ could have been emitted from the focal area. Although there is a possibility that the noise due to atmospherics (thunderbolts) shown in Panel 6 may affect the observation, ELF data (Panel 1) did not show any peaks in early December atmospherics, indicating ELF is immune to atmospherics. The observation of Panel 3 was originally monitoring EM waves from the planet Jupiter at $22.2 \mathrm{MHz}$ (Maeda and Tokimasa 1996) at a station quite close to the epicenter. The measuring system was a kind of interferometer, so that the unusual pulse that started at 05:20AM of January 17 was estimated to have come from the epicentral area. On the other hand, Panels 4 and 5 are related with anomalous transmission of man-made EM waves, which would need occurrence of disturbance in the ionosphere and/or troposphere above the focal area. Panel 4 shows unusual transmission of $\sim 10 \mathrm{kHz}$ Omega wave (Molchanov and Hayakawa 1998). Panel 5 shows unusual transmission of FM radio waves from FM stations beyond the line of sight (Kushida and Kushida 2002). 
Three-component geomagnetic monitoring was conducted by array networks in west Izu Peninsula and south Boso Peninsula, each array consisting of three closely spaced $(\sim 5 \mathrm{~km})$ stations with identical sensors (Figs. 18 and 19). The results of this ULF array observation will be reported in the accompanying paper (Hattori et al. 2004)

In summary, we observed that distinct anomalous changes started a few months before the outbreak of the 2000 swarm activity in the Izu Island region in both electric and magnetic fields measured at stations far apart.

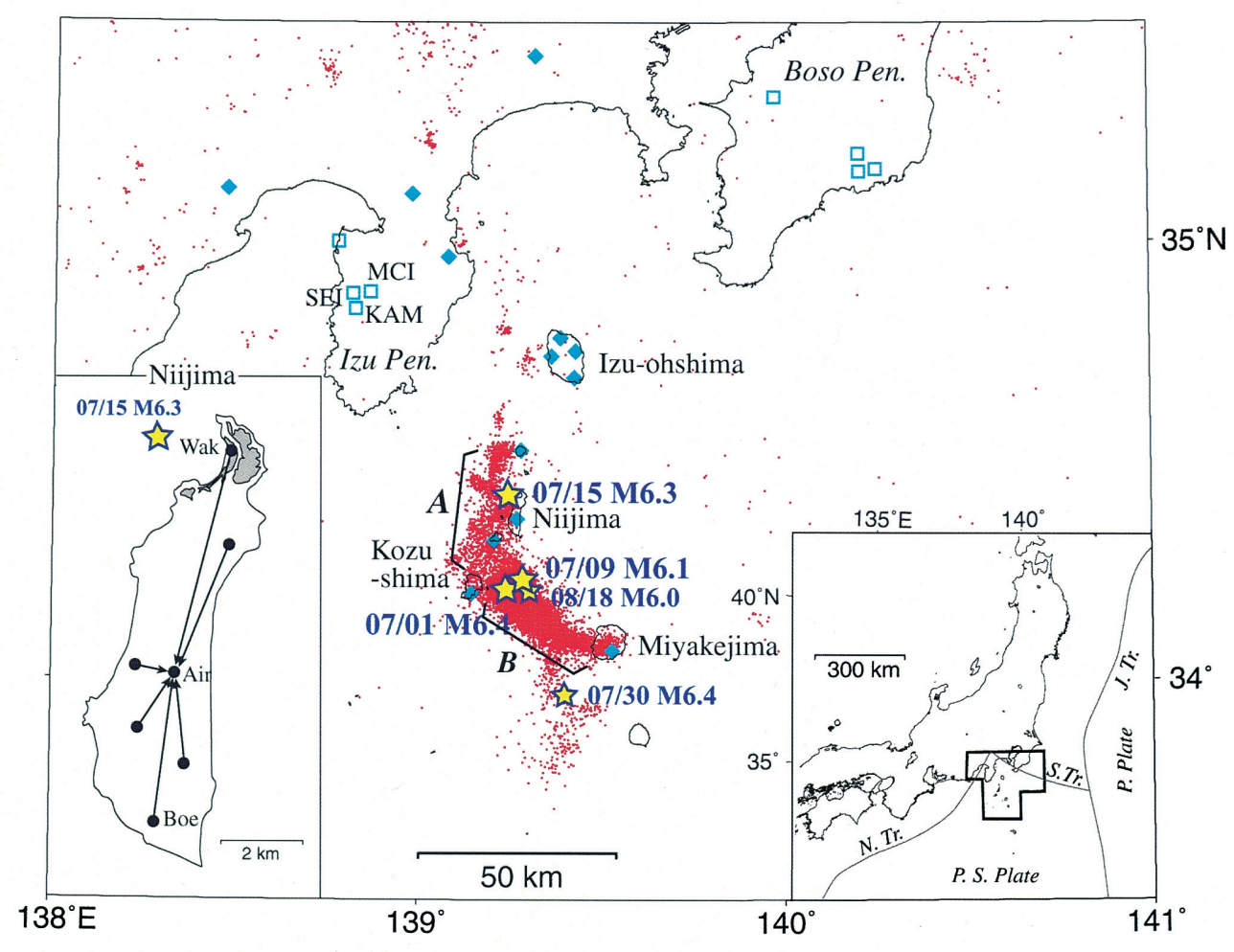

Fig. 18. Map of the Izu Island region. Red dots are $\mathrm{M} \geq 0$ earthquakes for June 1 - September 30, 2000. Yellow stars are $M \geq 6$ earthquakes. Diamonds: geoelectric stations; Open squares: geomagnetic stations. Inset in the left shows the long dipole configuration of Niijima station. A short dipole (not shown) is also installed at the far end of each long dipole centered at Air (Airfield). Shaded area around Wak is covered by basalt, while the rest of the island consists of rhyolite. 
(a)
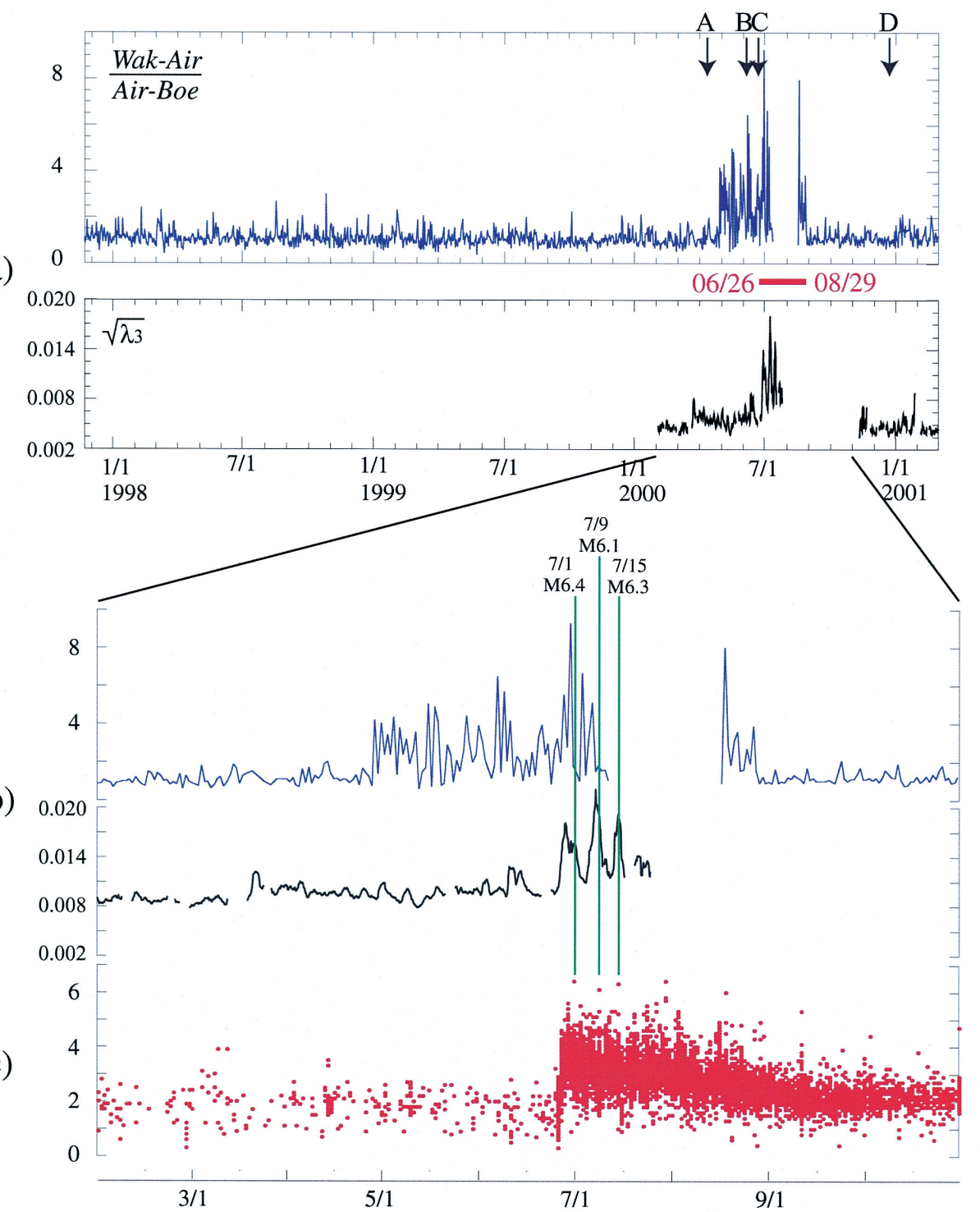

Fig. 19. Time change of the $0.01 \mathrm{~Hz}$ spectral intensity ratio (blue) of GPD at Wak-Air and Boe-Air dipoles, Niijima Island and that of the third principal component $\left(\sqrt{\lambda_{3}}\right)$ at $0.01 \mathrm{~Hz}$ of the geomagnetic field at Izu Peninsula array (black). a) For three year period, b) for January - October, 2000. Three $M \geq 6$ earthquakes in July are indicated by vertical green lines. c) Seismicity of the Izu Island region (brown dots). 


\subsection{Over-the Horizon Reception of VHF FM Waves}

Research on electromagnetic phenomena has investigated a wide frequency range. For instance, Kushida and Kushida, at the Yatsugatake South Base Observatory, were monitoring the transient reflections of VHF FM radio waves beyond the line of sight for meteor detection. They accidentally noted that their system recorded unusual signals on the night before the Kobe earthquake (See Fig. 17). They proposed that VHF FM radio waves traveling over the focal zone of an imminent earthquake are scattered to reach over-the-horizon distances. They devised a method of short-term prediction, now called the Kushida method. Since the mid1990's, the Kushidas have been practicing actual short-term prediction experiments (Kushida and Kushida 2002). The performance of the Kushida method during 2000 - 2003 has been evaluated for $\mathrm{M} \geq 5.5$ earthquakes by checking their predictions against the actual seismicity (Uyeda and Kumamoto 2004). The criteria for successful prediction were set as: the error in the date of the earthquake is less than 10 days, the error in the epicenter less than about $50 \mathrm{~km}$, and the error in magnitude is less than 1 Richter unit, from predicted time, space and magnitude windows respectively. It was found that about $40 \%$ of their predictions targeting $M \geq 5.5$ EQs were successful and about $30 \%$ of $M \geq 5.5$ earthquakes were successfully predicted. It was also found that even in unsuccessful predictions, meaningful signals were detected although the interpretation was not correct. The method is still far from perfect and its physical basis is uncertain (Pilipenko et al. 2001). However, the performance of the method justifies further investigation. Active cross-check experiments are now underway by several independent groups (e.g., Moriya et al. 2003; Takano et al. 2003; Kamogawa et al. 2003).

\section{REFLECTIONS AND PERSPECTIVE}

\subsection{Review}

\subsubsection{How did IFREQ start?}

EQ prediction has long been a dream of ours especially after the 1995 Kobe disaster. Despite strong and often pessimistic views held by both researchers and policy makers on the scientific communities ability to accurately predict earthquakes, the importance, necessity and urgency of this quest has never diminished. IFREQ was initiated at RIKEN in 1996 to explore the possibility that the newly emerging area of "Seismo-electromagnetics" could open up a new frontier in the science of short-term EQ prediction.

\subsubsection{The Main Objectives}

The main objectives were set as follows.

1) Confirmation of the existence of meaningful electric and/or magnetic precursors to EQs.

2) Clarification of the physical mechanism of such precursors.

Simple precursor searches in EQ prediction programs have been bitterly criticized. However, a purely deductive approach has been considered impractical in the science of short-term EQ 
prediction. The above two main objectives were to be pursued through a positive feedback process. IFREQ work started with construction of monitoring stations, i.e., geoelectric potential difference (GPD) stations and ULF geomagnetic stations. While seismo-EM phenomena were suggested to occur in a wide frequency range, IFREQ took up the lowest frequency, partly because its immediate interest was to check the VAN method and the ULF magnetic method which were reportedly quite promising and partly because phenomena in higher frequency ranges were being pursued by radio science experts. Toward the end of IFREQ, about 40 stations were in operation.

\subsubsection{Have the Objectives been Attained?}

\section{Achievements:}

Confirmation of the existence of VAN type SES and ULF magnetic signals have been attained as depicted in this report: Namely, SES were observed for $\mathrm{M}>5$ EQs occurring within $\sim 20 \mathrm{~km}$ of a station and pre-seismic magnetic signatures were observed at least for $\mathrm{M}>4$ EQ roughly satisfying $0.025 \mathrm{R}<\mathrm{M}-4.5$. Moreover, discoveries of phenomena attesting to extreme local underground heterogeneity in volcanic areas were made. In 2000, anomalies lasting for a few months were observed in both electric and magnetic fields before major swarm activity in the Izu Island region. Through the use of ULF magnetic measurements it was even possible to locate the origin of such signals.

\section{Reflections:}

Although it was anticipated, confirming the alleged pre-seismic signals in Japan was not an easy task, because the level of artificial noise is much higher than, for instance, Greece where DC-driven train railroad systems, heavy industry and population are much less. It was wishfully expected that, from a disaster prevention point of view in Japan, we would practically need to detect SES of M > 7 EQ only, so that their SES might be large enough to overcome the noise. However, during the IFREQ period, the seismicity in the Japanese region was very low and no such EQ occurred and it was necessary to work with smaller EQs. Another matter was that limited time and resources led to a choice between fewer but more elaborate stations in concentrated region(s) or as many stations as possible all over Japan with less sophistication. The merits and demerits of each option were obvious, but we took the latter strategy as we did not want to miss rare opportunities that may arise. This decision did allow us to catch more opportunities and confirm the existence of precursors, but many cases were not truly ideal, as anticipated.

\subsubsection{Termination of IFREQ}

In January 2000, a mid-term external review was conducted by an international group of seven renowned scientists, chaired by Professor H. Kanamori, California Institute of Technology. The review was extremely favorable and strongly recommended IFREQ's continuation to a second five year phase. Based upon this recommendation, preparatory work was commenced in RIKEN. At the request of Science and Technology Agency, another end-term 
external review was made in June 2001 by a group comprised of four Japanese scientists headed by Professor N. Fujii, Nagoya University. This Review also recommended continued support to IFREQ for its second phase. However, for reasons not clearly stated, termination of IFREQ was announced shortly before the second review was presented. The RIKEN Frontier Research System Advisory Council (FRAC) chaired by Professor Y. Nishijima, in its second meeting held in June 2001, strongly urged RIKEN to make every possible effort to maintain the IFREQ research. However the initial decision to terminate IFREQ was not overturned. We feel that this course of action, which has ignored the scientific recommendations of external reviews, has not only deterred the progress of science but jeopardized the whole review system.

\subsection{Progress of Seismo-electromagnetics at Home and Abroad}

During the IFREQ period and afterwards, seismo-EM research has made notable progress. ULF magnetic observation is actively made in Kamchatka as a continuation of our collaboration. ELF, VLF and VHF emission studies at Chubu, Tokai and Hiroshima Municipal Universities, VLF and VHF transmission anomaly studies at Electro Telecommunication, Chiba, Hokkaido and Tokyo Gakugei Universities are also producing promising results. In the private sector, the Kushida method at Yatsugatake South Base Observatory has been issuing short term predictions based on anomalous transmission of FM radio waves attracting strong attention from the scientific community. IFREQ has been cooperating with all of these groups. A nationwide forum called SEMScore (Seismic Electric Magnetic Signals Core) has been formed to promote mutual communication and collaboration and IFREQ has been playing a central role in its activity.

The almost explosive rise of seismo-EM is not limited to Japan. Internationally too, the research has made rapid progress. To name a few countries, Taiwan, France, Greece, Italy, Armenia, Mexico, Russia, China and the USA are especially active in this field. In France, a satellite called DEMETER was successfully launched on June 29, 2004 for global seismo-EM monitoring. Recognizing this trend, International Union of Geodesy and Geophysics (IUGG) established the Inter-association Working Group on Electro Magnetic Study on Earthquakes and Volcanoes (EMSEV) in 2002 and the authors of this paper (S.U. and T.N.) are serving as its first chairman and secretary. With hundreds of original papers being presented at national and international meetings a new global tide is rising in favor of seismo-EM.

\section{CONCLUSIONS}

Continued efforts are still needed to collect and accumulate more data since EQ phenomena are so diverse. In doing so, there is a continuous need for positive feedback from laboratory and field experiments to aid theoretical development and modeling. Selection of methods by relative virtue will help economize on resources and efforts. Yet simultaneous observation via methods that deal with different frequency phenomena will be essential for making results more credible.

Another important point will be to integrate seismo-EM findings with those of other equally 
rapidly advancing disciplines, notably physics, seismology, geodesy, hydrology and geochemistry. Through this approach, seismo-EM will be able to contribute to the understanding of the physics of seismicity as a critical phenomenon.

Some important specific future tasks and problems are:

1) Measurements at the seafloor near subducting plate boundaries, namely deep ocean trenches, where giant EQs occur. This will need development of hardware, but seafloor measurements have advantages of closeness to the focal areas and much less natural and manmade noise.

2) One of the most important and basic outstanding questions to solve is the mechanism of the proposed Lithosphere-Atmosphere-Ionosphere (LAI) coupling as the cause of the transmission anomaly of EM waves. We have to confirm pre-seismic ionospheric electron density variation by direct sounding from the ground and/or by cooperation with the French seismoEM monitoring satellite DEMETER. Various LAI coupling mechanisms; for example, EM coupling, Geochemical Coupling, and Mechanical Coupling, have been proposed for the origin of pre-seismic ionospheric disturbance; however none has yet been verified. In any case, pre-seismic activity in the solid earth has to influence the upper atmosphere. To narrow down the proposed mechanisms, the reality of assumed premises regarding them must first be checked. This includes the checking of existence/non-existence of pre-seismic atmospheric electric field anomaly, positive charges on the ground surface, and ground motions that may generate the internal atmospheric gravity waves. Obviously, more intensive cooperation with experts in diverse disciplines will be needed to attack these targets.

3) Physics of DC to ULF/ELF signal generation/transmission now appears more or lesstractable, but emergence of VLF to VHF emission from the focal zone through the conducting earth remains a puzzling question. The detection of pre-seismic high frequency AE related to distant $\mathrm{EQ}$, discovered by IFREQ, is another riddle. Both seem to require sources close to observation sites and solving these problems will contribute to understand the EQ preparation process.

4) Role of water in the seismogenic process is also an important issue and the EM investigation may be particularly useful in detecting the movement of water in the earth.

5) Science dealing with such natural phenomena as earthquakes takes time and long term funding is mandatory. We regret deeply that both RIKEN and NASDA seismo-electromagnetics related frontier projects have been terminated. In spite of these circumstances, research in this field is making significant and rapid progress both in Japan and globally. We will continue in our utmost efforts to contribute to this science and to the welfare of humankind by eventually attaining practical short-term EQ prediction methods.

Acknowledgments The IFREQ research was funded by the Science and Technology Agency (now Ministry of Education, Culture, Sports, Science and Technology) of Japan through RIKEN. We are grateful to all concerned.

\section{REFERENCES}

Andrews, R. A., 1992: The Parkfield earthquake prediction of October 1992: the Emergency Services response. Earthquakes \& Volcanoes, 23, No. 4, 170-174. 
Balassanian, S., A. Mouradian, A. Sahakian, S. Kalinin, M. Babayan, and A. Pogossian, 1997: The invesitgation of electromagnetic precursors to earthquakes in Armenia. Annali di Geofisica, XL, 209-225.

Bernard, P., 1992: Plausibility of long distance electrotelluric precursors to earthquakes.J. Geophys. Res., 97, 17531-17546.

Chen,Y. T., Z. L. Chen, and B. Q. Wang, 1990: Seismological studies of earthquake prediction in China: a review. In: Boschi E., and M. Dragoni (Eds.), Earthquake Prediction, IL CIGNO GALILEO GALILE, 71-109.

Corwin, R. F., and H. F. Morrison, 1977: Self-potential variations preceding earthquakes in central California. Geophys. Res. Lett., 4, 171-174.

Dobrovolsky I. P., N. L.Gershenzon, and M. B.Gokhberg, 1989: Theory of electrokinetic effects occurring at the final stage in the preparation of a tectonic earthquake. Phys. Earth Planet Inter., 57. 144-156.

Dologlou, E., 1993: A three year continuous sample of officially documented predictions issued in Greece using the VAN method. Tectonophys., 224, 189-202.

Drakopoulos J., G. N. Stavrakakis, and J. Latoussakis, 1993: Evaluation and interpretation of Thirteen official VAN-telegrams for the period September 10, 1986 to April 28, 1988. Tectonophys., 224, 223-236.

Fedorov, E., V. Pilipenko, and S. Uyeda, 2001: Electric and magnetic fields generated by electrokinetic processes in a conductive crust. Phys. Chem. Earth, 26, 793-799.

Fischbach, D. B., and A. S. Nowick, 1955: Deformation-Induced charge flow in $\mathrm{NaCl}$ crystals. Phys. Rev., 99, 1333-1334.

Fischbach, D. B., and A. S. Nowick, 1958: Some transient electrical effects of plastic deformation in $\mathrm{NaCl}$ crystals. J. Phys. Chem. Solids, 5, 302-315, 1958.

Fitterman, D. V., 1981: Correction to Theory of electrokinetic-magnetic anomalies in a faulted half space. J. Geophys. Res., 86, 9585-9588.

Fraser-Smith, A. C., A. Bernardi, P. R. McGill, M. E. Ladd, R. A. Helliweill, and O. G. Villard Jr., 1990: Low-frequency magnetic field measurements near the epicenter of the MS 7.1 Loma Prieta earthquake. Geophys. Res. Lett., 17, 1465-1478.

Gershenzon N., and M. Gokhberg, 1993: On the origin of electrotelluric disturbances prior to an earthquake in Kalamata, Greece. Tectonophys., 224, 169-174.

Gorbatikov, A., O.Molchanov, M. Hayakawa, S. Uyeda, K. Hattori, T. Nagao, H. Tanaka, A. Nikolaev, and P. Malltsev, 2002: Acoustic emission possibly related to earthquakes, observed at Matsushiro, Japan and its implications. In: Hayakawa M., and O. Molchanov (Eds.), Seismo Electromagnetics: Lithosphere - Atmosphere - Ionosphere Coupling, TERRAPUB, Tokyo, 1-10.

Gruszow, S., J. Rossignol, A. Tzanis, and L. Le Mouel, 1996: Identification and analysis of electromagnetic signals in Greece: the case of the Kozani earthquake VAN prediction. Geophys. Res. Lett., 23, 2025-2029.

Hadjicontis V., and C. Mavromatou, 1994: Transient electric signals prior to rock failure under uniaxial compression. Geophys. Res. Lett., 21, 1687-1690. 
Hadjicontis V., and C. Mavromatou, 1996: Laboratory investigation of the electrical signals preceding earthquakes. In: J. Lighthill (Ed.), A Critical Review on VAN, World Scientific, Singapore, 105-117.

Hamada, K., 1990: Present state of earthquake prediction system in Japan, In: Boschi E., and M. Dragoni (Eds.), Earthquake Prediction, IL CIGNO GALILEO GALILEI, 33-69.

Hattori, K., 2004: ULF geomagnetic changes associated with large earthquakes. TAO, 15, 329-360.

Hayakawa, M., R. Kawate and O.A. Molchanov, 1996: Ultra-low- frequency signatures of the Guam earthquake on 8 August, 1993 and their implication.J. Atmos. Electr., 16, 193-198.

Hayakawa, M. (Ed.), 1999: Atmospheric and Ionospheric Electromagnetic Phenomena associated with Earthquakes, TERRAPUB, Tokyo, 996p.

Hayakawa, M., and O. Molchanov (Eds.), 2002: Seismo Electromagnetics, TERRAPUB, Tokyo, 477p.

Huang, Q., G. Sobolev, and T. Nagao, 2001: Characteristic of the seismic quiescence and activation patterns before the $\mathrm{M}=7.2$ Kobe earthquake, January 17, 1995.Tectonophys., 337, 99-116.

Ikeya, M., T. Komatsu, Y. Kinoshita, K. Teramoto, K. Inoue, M. Gondou, and T. Yamamoto, 1997: Pulsed electric field before Kobe and Izu earthquakes from seismically - induced anomalous animal behavior (SAAB). Episodes, 20, 253-260.

Ishido, T., and H. Mizutani, 1981: Experimental and theoretical basis of electrokinetic phenomena in rock-water systems and its applications to geophysics.J. Geophys. Res., 86, 1763-1775.

Ishido, T., and J. W. Pritchett, 1999: Numerical simulation of electrokinetic potentials associated with subsurface fluid flow. J. Geophys. Res., 104, 15,247-15,259.

Jouniaux, L., and J. P. Pozzi, 1995a: Permeability dependence of streaming potential in rocks for various fluid conductivities. Geophys. Res. Lett., 22, 485-488.

Jouniaux, L., and J. P. Pozzi, 1995b: Streaming potential and permeability of saturated sandstones under triaxial stress: Consequences for electrotelluric anomalies prior to earthquakes. J. Geophys. Res., 100, 10197-10209.

Kamogawa, M., H. Fujiwara, H. Sakata, J. Y. Liu, H. Ofuruton, and Y. J. Chuo, 2003: Seismoatmospheric disturbances observed by anomalous transmission of VHF electromagnetic waves. IUGG 2003 Sapporo Abstracts, A. 189, JWS01/02P/D-034.

Keilis-Borok, V. I., and V. G. Kossobokov, 1990: Premonitory activation of earthquake flow: algorithm M8. Phys. Earth Planet. Inter., 61, 73-83.

Koizumi, N., E. Tsukuda, O. Kamigaichi, N. Matsumoto, M. Takahashi, and T. Sato, 1999: Preseismic changes in ground water level and volumetric strain associated with earthquake swarms off the east coast of the Izu Peninsula, Japan. Geophys. Res. Lett., 26, 3509-3512.

Kondo, S., S. Uyeda, and T. Nagao, 2002: The selectivity of the Ioannina VAN station. $J$. Geodynamics, 33, 433-461. 
Kopytenko, Y. A., T. G. Matishvili, P. M. Voronov, E. A. Kopytenko, and O. A. Molchanov, 1993: Detection of ultra-low-frequency emissions connected with the Spitak earthquake and its aftershock activity, based on geomagnetic pulsations data at Dusheti and Vardzia observatories. Phys. Earth Planet. Inter., 77, 85-95.

Keilis-Borok, V. I., and V. G. Kossobokov, 1990: Premonitory activation of earthquake flow: algorithm M8. Phys. Earth Planet. Inter., 61, 73-83.

Kushida, Y., and R. Kushida, 2002: Possibility of earthquake forecast by radio observations in the VHF band. J. Atmosph. Electricity, 22, 239-255.

Lazarus D., 1996: Physical mechanisms for generation and propagation of seismic electric signals. In: Lighthill J. (Ed.), A Critical Review of VAN, World Scientific, Singapore, 91-96.

Lighthill, J. (Ed.), 1996: A Critical Review of VAN, World Scientific, 376p.

Lorne, B., F. Perrier, and J. P. Avouac, 1999a: Streaming potential measurements, 1. Properties of the electrical double layer from crushed samples. J. Geophys. Res., 104, 1785717877.

Lorne, B., F. Perrier, and J. P. Avouac, 1999b: Streaming potential measurements, 2. Relationship between electrical and hydraulic flow patterns from rock samples during deformation. J. Geophys. Res., 104, 17879-17896.

Massenet, F., and P. V. Ngoc, 1985: Experimental and theoretical basis of self-potential phenomena in volcanic areas with reference to results obtained on Mount Etna (Sicily). Earth Planet. Sci. Lett., 73, 415-429.

Mizutani, H., and T. Ishido, 1976: A new interpretation of magnetic field variation associated with the Matsushiro earthquakes. J. Geomagn. Geoelectr., 28, 179-188.

Mogi, T., Y. Tanaka, D. S. Widarto, E. M. Arsay, N. T Puspito, T. Nagao, Y. Kanda, and S. Uyeda, 2000: Geoelectric potential difference monitoring in southern Sumatra, Indonsia - Co-seismic change. Earth Planets. Space, 52, 245-252.

Moriya, T., T. Mogi, M. Takada, and M. Kasahara, 2003 :Modification of Kushida's method and preliminary result - high possibility method for earthquake forecast based on the exploration for VHF scatterer in the atmosphere. IUGG 2003 Sapporo Abstracts, A. 188, JWS01/02P/D-032.

Mulargia, F., and Gasperini P., 1992: Evaluating the statistical validity beyond chance of 'VAN' precursors. Geophys. J. Intern. 111, 32-44.

Nagao T., S. Uyeda, Y. Asai, and Y. Kono, 1996a: Anomalous changes in geoelectric potential preceding four earthquakes in Japan. In: Lighthill J. (Ed.), A Critical Review of VAN, World Scientific, Singapore, 292-300.

Nagao T., M. Uyeshima, and S. Uyeda, 1996b: An independent check of VAN's criteria for signal recognition. Geophys. Res. Lett., 23, 1441-1444.

Nagao, T., Y. Orihara, T. Yamaguchi, I. Takahashi, K. Hattori, Y. Noda, K. Sayanagi, and S. Uyeda, 2000: Co-seismic geoelectric potential changes observed in Japan. Geophys. Res. Lett., 27, 1535-1538.

Nagao, T., Y. Enomoto, Y. Fujinawa, M. Hata, M. Hayakawa, Q. Huang, J. Izutsu, Y. Kushida, K. Maeda, K. Oike, S. Uyeda, and T. Yoshino, 2002: Electromagnetic anomalies associated with 1995 Kobe earthquake. J. Geodynamics, 33, 401-411. 
Nishimura, A., Y. Ueno, S. Fujiwara, I. Ijiri, T. Fukunaga, S. Hishida, K. Hatake, A. Tanegashima, H. Kinoshita, Y. Mizoi, and Y. Tatsuno, 1997: Statistical Report on Casualty of the Great Hanshin Earthquake. J. Advance Legal Medicine, 3, 346-349,

Nowick, A. S., 1996: The golden age of crystal defects. Annu. Rev. Mater. Sci., 26, 1-19.

Orihara, Y., Y. Noda, T. Nagao, and S. Uyeda, 2002: A possible case of SES selectivity at Kozu-shima Island, Japan. J. Geodynamics, 33, 425-432.

Pham, V., D. Boyer, G. Chouliaras, J. Le Mouel, J. Rossignol, and G. Stavrakakis, 1998: Characteristic of electromagnetic noise in the Ioannina region (Greece); a possible origin for so called "Seismic Electric Signal" (SES). Geophys. Res. Lett., 25, 2298-2232.

Pham, V., D. Boyer, J. Le Mouel, G. Chouliaras, and G. Stavrakakis, 1999: Electromagnetic signals generated in the solid Earth by digital transmission of radio-waves as a plausible source for some so called "Seismic Electric Signals". Phys. Earth Planet Inter., 114, 141-163.

Pham, V., D. Boyer, G. Couliaras, A. Savvaidis, G. Stavrakakis, and J. L. Le Mouel, 2002: Sources of anomalous transient electric signals (ATESs) in the ULF band in the Lamia region(Central Greece): electrochemical mechanisms for their generation. Phys. Earth Planet Inter., 130, 209-233.

Pilipenko, V., S. Shalimov, S. Uyeda, and H. Tanaka, 2001: Possible mechanism of the overhorizon reception of FM radio waves during earthquake preparation period. Proc. Japan Acad., 77, Ser. B, 125-130.

Revil, A., P. A. Pezard, and P. W. J. Glover, 1999: Streaming potential in porous media 1. Theory of the zeta potential.J.Geophys. Res., 104, 20,021-20,031.

Rikitake, T., 1976: Earthquake Prediction, Elsevier, 357p.

Sarlis, N., M., Lazaridou, P. Kapiris, and P. Varotsos, 1999: Numerical model of the selectivity effect and the GV/L criterion. Geophys. Res. Lett., 26, 3245-3248.

Scholz, C. H., L. R. Sykes, and Y. P. Aggarwal, 1973: Earthquake prediction: A physical basis. Science, 181, 803-810.

Silver, P. G., and H. Wakita, 1996: A search for earthquake precursors. Science, 273, 77-78.

Slifkin L., 1996: A dislocation model for seismic electric signals. In: Lighthill J., (Ed.), A Critical Review of VAN, World Scientific, Singapore, 97-104.

Sobolev G. A., 1975: Application of electric method to the tentative short-term forecast of Kamchatka earthquakes. Pageoph, 113, 229-235 .

Sobolev, G., and Yu. Tyupkin, 1997: Low-seismicity precursors of large earthquakes in Kamchatka. Volc. Seismol., 18, 433-446.

Sobolev, G. A., Q. Huang, and T. Nagao, 2002: Phases of earthquake's preparation and by chance test of seismic quiescence anomaly. J. Geodynamics, 33, 413-424.

Surkov V., S. Uyeda, H. Tanaka, and M. Hayakawa, 2002: Fractal Properties of medium and seismoelectric phenomena. J. Geodynamics, 33, 477-487.

Takano, T., K. Sakai, A. Yamada, H. Higasa, and S. Shimakura, 2003: Electromagnetic phenomena possibly associated with earthquakes obtained with broadband observations. IUGG 2003 Sapporo Abstracts, A. 188, JWS01/02P/D-030. 
Tanaka, H., 2002: Log-periodic modulation to power law of change in the geoelectric potential difference observed on Niijima Island prior to volcanic and seismic activation in the Izu island region, Japan 2000. Proc. Japan Acad., 78, Ser.B, 271-286.

Utada, H., 1993: On the physical background of the VAN earthquake prediction method. Tectonophysics, 224, 153-160.

Uyeda, S., 1998: The VAN method of earthquake prediction. EOS, Nov. 24, pages 573, 579, 580.

Uyeda, S., and K. Al-Damegh, 1999: Evaluation of VAN method. In: Hayakawa M. (Ed.), Atmospheric and Ionospheric Electromagnetic Phenomena associated with Earthquakes, TERRAPUB, Tokyo, 53-69.

Uyeda S., K. Al-Damegh, E. Dologlou, and T. Nagao, 1999: Some relationship between VAN seismic electric signals (SES) and earthquake parameters. Tectonophys., 304, 41-55.

Uyeda, S., T. Nagao, Y. Orihara, Y. Yamaguchi, and T. Takahashi, 2000: Geoelectric potential changes: Possible precursors to earthquakes in Japan. Proc. Nat. Acad. Sci., 97, 4561-4566.

Uyeda, S., and S. Park (Eds.), 2002: Recent Investigations of electromagnetic Variations Related to Earthquakes. J. Geodynamics, 33, 377-570.

Uyeda, S., M. Hayakawa, T. Nagao, O. Molchanov, K. Hattori, Y. Orihara, K. Gotoh, Y. Akinaga, and H. Tanaka, 2002: Electric and magnetic phenomena observed before the volcano-seismic activity in 2000 in the Izu Island region, Japan.Proc. Nat. Acad. Sci., 99, 7352-7355.

Uyeda, S., and Meguro, 2004: Earthquake Prediction, Seismic Hazard and Vulnerability. In "The State of the Planet", (S. Sparks, Ed.), IUGG/AGU Monograph (in press).

Uyeda, S., and H. Tanaka, 2004: Maxwell's equations and earthquakes. Physics World, 17, No.2, 21-22.

Uyeda, S., and A. Kumamoto, 2004: Evaluation of the Kushida method of short-term earthquake prediction. Proc. Japan Acad., Ser. B, Phys. Biolog. Sciences, 80, no.3, 140-147.

Varotsos, P., and K. Alexopouloss, 1984 a, b: Physical properties of the variations of the electric field of the earth preceding earthquakes. Tectonophys., 110, 73-98, and 99 125.

Varotsos, P., and K. Alexopoulos, 1986: Thermodynamics of Point Defects and their Relation with Bulk Properties. North Holland, Amsterdam, 474p., 136-142, 403-406, 410-412, 417-420.

Varotsos, P., K. Alexopoulos, and M. Lazaridou, 1993a: Latest aspects of earthquake prediction in Greece based on seismic electric signals II. Tectonophys., 224, 1-37.

Varotsos, P., K. Alexopoulos, M. Lazaridou-Varotsou, and T. Nagao, 1993b: Earthquake predictions issued in Greece by seismic electric signals since February 6, 1990. Tectonophys., 224, 269-288.

Varotsos, P., M. Lazaridou, K. Eftaxias, G. Antonopoulos, J. Makris, and J. Kopanas, 1996a: Short term earthquake prediction in Greece by Seismic Electric Signals. In: Lighthill, J. (Ed.), A Critical Review on VAN, World Scientific, Singapore, 29-76. 
Varotsos, P., K. Eftaxias, M. Lazaridou, E. Dologlou, and V. Hadjicontis, 1996b: Reply to "Probability of chance correlations of earthquakes with predictions in areas of heterogeneous seismicity rate: The VAN case" by M. Wyss and A. Allmann. Geophys. Res. Lett., 23, 1311-1314.

Varotsos, P., N. Sarlis, M. Lazaridou, and P. Kapiris, 1998: Transmission of stress induced electric signals in dielectric media. J. Appl. Phys., 83, 60-70.

Varotsos, P., N. Sarlis, and E. Skordas, 2002: Long range correlations in the electric signals that precede rupture. Phys. Rev. E., 66, 011902-1-011902-7.

Varotsos, P., N. Sarlis, and E. Scordas, 2003a: Electric fields that "arrive" before the time derivative of the magnetic field prior to major earthquakes.Phys. Rev. Lett., 91, 148501.

Varotsos, P., N. Sarlis, and E. Skordas, 2003b: Long-range correlations in the electric signals that precede rupture: Further investigation. Phys. Rev. E., 67, 021109-1-0211109-13.

Varotsos, P., N. Sarlis, and E. Skordas, 2003c: Attempt to distinguish electric signals of a dichotomous nature. Phys. Rev. E., 68, 031106-1 - 031106-7.

Varotsos, P., 2004: Thr Physics of Seismic Electric Signals, TERRAPUB, Tokyo.

Wyss, M., and A. Allmann, 1996: Probability of chance correlations of earthquakes with predictions in areas of heterogeneous seismicity rate: The VAN case. Geophys. Res. Lett., 23, 1307-1310.

Yoshida, S., O. C. Clint, and P. R. Sammonds, 1998: Electric potential changes prior to shear fracture in dry and saturated rocks. Geophys. Res. Lett., 25, 1577-1580.

Yoshida, S., 2001: Convection current generated prior to fracture.J. Geophys. Res., 106, 2103-2130. 